\title{
O ENSINO DOS ESTUDOS ORGANIZACIONAIS \\ NAS INSTITUIÇÕES BRASILEIRAS: \\ UM ESTUDO EXPLORATÓRIO NOS CURSOS DE \\ PÓS-GRADUAÇÃO STRICTO SENSU DE ADMINISTRAÇÃO
}

\author{
TEACHING ORGANIZATIONAL STUDIES \\ IN BRAZILIAN INSTITUTIONS: \\ AN EXPLORATORY STUDY \\ OF GRADUATE MANAGEMENT DEGREE COURSES
}

\author{
Recebido em: 03/04/2013 - Aprovado em: 29/05/2013 \\ Avaliado pelo sistema double blind review \\ Editora Científica: Manolita Correia Lima
}

\section{CLAUDIANI WAIANDT cwaiandt@ig.com.br TÂNIA FISCHER \\ UNIVERSIDADE FEDERAL DA BAHIA}

\section{RESUMO}

O ensino de Estudos Organizacionais (EO) na Administração constrói-se a partir de mudanças econômicas, políticas, e socioculturais que determinam ideologias e olhares diferenciados que conformam o campo. O professor possui autonomia para organizar, desenvolver e avaliar esse ensino, todavia esta autonomia é relativa aos conhecimentos, aos hábitos, às habilidades e aos valores vivenciados na prática pedagógica, que sobremaneira são influenciados pelas contingências institucionais. Portanto, o currículo é inequivocadamente uma construção social. Buscando construir essa realidade, propôs-se a análise de como se ensina o campo dos EO nos cursos de mestrado e doutorado em nove Programas de Pós-Graduação Stricto Sensu no Brasil. Para tal, realizou-se uma pesquisa qualitativa exploratória por meio de análise documental dos currículos e planos de ensino de dezessete professores de pós-graduação, bem como entrevistas semiestruturadas. Como resultado, verificou-se que o ensino dos EO não é determinado isoladamente por docentes, mas construído com os seus pares; que se constitui em eixo estruturante dos mestrados; que o conhecimento está reunido em basicamente três formas de organização (histórico, por tópicos ou diálogos), que a diversidade de autores referenciados reflete a pluralidade da formação acadêmica e interdisciplinar do corpo docente.

Palavras-chave: Estudos Organizacionais; administração; ensino; pós-graduação; história.

\begin{abstract}
Teaching Organizational Studies (OS) in Management is based on the economic, political, and socio-cultural changes that determined special ideologies and points of view that shape the field. The teacher has autonomy to organize, develop and evaluate this teaching, but this autonomy is limited by the knowledge, habits, skills and values experienced in their teaching practice, which are heavily influenced by institutional contingencies. There is, therefore, no doubt that the curriculum is a social construction. An examination of how OS is taught in nine graduate degree programs in Brazil was proposed, in order to build this reality. To this end, we carried out exploratory, qualitative research through documentary analysis of curricula and teaching plans of seventeen graduate professors, as well as semistructured interviews. The results indicate that the teaching of OS: is not determined solely by the professors, but built in conjunction with their peers; is constituted of the structural axis of the Masters' degrees; has knowledge that is basically grouped in three organizational forms (historic, by topic or dialogues); has a diversity of academic and interdisciplinary faculty that reflects the diversity of the authors referenced.

Keywords: Organizational Studies; management; teaching; graduate studies; history.
\end{abstract}




\section{INTRODUÇÃO}

O ensino de Estudos Organizacionais (EO) reflete as mudanças econômicas, políticas, e socioculturais que determinam ideologias e olhares diferenciados que conformam o campo. Embora o professor possua autonomia para organizar, desenvolver e avaliar o ensino na formação do estudante de administração, esta autonomia é relativa aos conhecimentos, aos hábitos, às habilidades e aos valores vivenciados na prática pedagógica, pois o professor é influenciado pelas contingências institucionais.

O processo de produção do currículo, mais detidamente, o de ensino, não é um processo lógico, mas social, no qual convivem lado a lado os fatores lógicos, intelectuais, com determinantes sociais menos "formais" tais como interesses, rituais, conflitos simbólicos e culturais, necessidades de legitimação e de controle, propósitos de dominação dirigidos por fatores ligados à classe, à raça, ao gênero (GOODSON, 1995). Desta forma, o currículo não é constituído de conhecimentos válidos, mas de conhecimentos socialmente considerados válidos num determinado momento e numa determinada sociedade.

Nesse sentido, a política do Ministério da Educação (MEC) (principalmente o Sistema de Avaliação da Pós-Graduação) acaba por reorientar os objetivos da educação na sala de aula, assim como a produção acadêmica na área de Administração divulga temas que influenciam os docentes na seleção do conhecimento que será ensinado. Os interesses institucionais dos programas, bem como os interesses individuais do corpo docente influenciam o que e como será ensinado ao estudante. Assim, o professor não vive em uma ilha cercado por águas calmas, mas numa arena cercada por diferentes tipos de opiniões e interesses.

No Brasil, o debate sobre ensino tem aumentado na academia, verificandose o interesse por temas relacionados com o currículo dos cursos de graduação, as estratégias de ensino-aprendizagem, métodos de avaliação, mais especificamente, o conteúdo ensinado sobre a Administração, como Castro (198I), Motta (1983), Fischer (1993, 200I, 2003), Mattos e Bezerra (1999), Skora e Mendes (200I), Godoy, Moreira e Takei (2002), Fischer, Waiandt e Silva (2009). 
Apesar desse interesse da academia, não se realizou um estudo aprofundado sobre o ensino dos EO nos Programas de Pós-Graduação Stricto Sensu em Administração no Brasil. Nesse sentido se dá a contribuição desse artigo: como se ensina o campo de EO nos mestrados e doutorados acadêmicos?

Com base nessa questão efetivou-se uma pesquisa qualitativa exploratória por meio de uma pesquisa documental na base de dados da CAPES sobre os cursos de mestrado e doutorado acadêmicos. Após esta etapa, nove programas foram selecionados: a Fundação Getúlio Vargas do Rio de Janeiro (FGv/RJ), Fundação Getúlio Vargas de São Paulo (FVG// sP), Universidade Federal da Bahia (UfBA), Universidade Federal de Minas Gerais (UfMG), Universidade Federal de Pernambuco (UfPE), Universidade Federal do Paraná (UFPR), Universidade Federal do Rio Grande do Sul (UfRGS), Universidade Federal de Santa Catarina (UFSC) e Universidade de Brasília (UNB). A escolha foi feita devido à importância histórica, os programas estão entre os primeiros criados no país, possuem mestrado e doutorado acadêmicos e seus docentes são representativos do campo de EO. Após essa seleção, foram realizadas dezessete entrevistas semiestruturadas com os professores que lecionam/lecionaram disciplinas do campo de Estudos Organizacionais nesses programas, além de uma análise dos planos de ensino de suas disciplinas e do seu currículo Lattes. Todo o material coletado passou por uma análise de conteúdo criteriosa sendo organizado em categorias para análise.

Com base nos resultados da pesquisa, espera-se contribuir para a academia evidenciando a importância de EO como eixo estruturador dos cursos de Administração, já que os problemas que emergem da prática nas organizações (inclusive nas Instituições de Ensino) relacionam-se diretamente com a formação do estudante, consequentemente, com a dinâmica dos Cursos de Pós-Graduação Stricto Sensu em Administração, evidenciando a complexidade da organização curricular, contextualizada territorial e culturalmente.

Após essa introdução, o próximo tópico trata do currículo como uma construção social, o seguinte enfatiza esta discussão na área de 
Administração, na sequência apresenta-se a metodologia de pesquisa focada no estudo qualitativo, logo após expõe e analisa o estudo realizado sobre o currículo e o ensino de EO, e por fim são apresentadas as considerações finais. 


\section{A CONSTRUÇÃO SOCIAL DO CURRÍCULO}

A compreensão do ensino sobre o campo de Estudos Organizacionais não é uma tarefa simples, pois o conhecimento "é uma construção social que reflete padrões de status e hierarquias sociais existentes na sociedade global" (KINCHelOe, 200I, p. 8). Por isso, dificilmente, entender-se-ia ensino somente estudando o que está registrado, escrito, como os programas do curso, as ementas das disciplinas, as atas das reuniões, como é ressaltado pela história tradicional. É preciso buscar a contribuição de cada ator nesse processo de re/produção do conhecimento, além de explorar a natureza da interpretação e a sua relação com o refazer da prática.

A teoria da História do Currículo e das Disciplinas Escolares (BITTENCOURT, 2003; CHERVEL, I990; GOODSON, 1995, 200I, 2003; JULIA, 2002; SANTOS, I990) explica o conhecimento não como algo que se transmite aos alunos de um modo acrítico - uma reprodução de conhecimentos impostos externamente, mas de conhecimentos considerados socialmente válidos por determinado grupo social, em um período de tempo.

Esse modo construcionista de examinar o currículo, mais especificamente as matérias de ensino, do ponto de vista histórico e social, emergiu por volta da década de 1970, quando a sociologia do conhecimento precipitara o advento de uma Nova Sociologia da Educação, na Inglaterra, e a Sociologia do Currículo, na América do Norte (Julia, 2002; Pessanha; Daniel; MENEGAZZO, 2004; ROCHA, 2003; SANTOS, I990; SOUZA-JUNIOR; GALVÃO, 2005). Uma contribuição importante foi dada por Ivor Goodson (I995, 200I, 2003), o qual, influenciado pelos estudos dos sociólogos do conhecimentor, buscou entender as percepções subjetivas e a construção social da realidade, no sentido de caracterizar as esferas e níveis em que esse currículo é produzido e negociado.

Simultaneamente aos estudos realizados na Inglaterra e EUA, surgiu, na França, um campo de pesquisa sobre a história das disciplinas escolares (AIRES; ERN, 2005; BITTENCOURT, 2003; CHERVEL, I990; JULIÁ, 2002; SANTOS, 1990), fundamentada na história da Educação, que investiga "a gênese e os diferentes momentos históricos em que se constituem os saberes escolares, 
visando perceber a sua dinâmica, as continuidades e descontinuidades no processo de escolarização" (BITTERCOURT, 2003, p. 15).

Os historiadores do currículo procuram alertar para a necessidade de desconfiar de relatos que atribuem às palavras e conceitos sempre os mesmos significados, verificando os diferentes significados que, por meio da história, podem ter sido atribuídos às mesmas palavras. Particular atenção deve-se ter em relação à atribuição e conteúdos fixos para uma dada disciplina escolar (ROCHA, 2003). A Administração é um exemplo, visto que tanto os conteúdos que hoje são reconhecidos como pertencentes a essa disciplina já foram ensinados por outras, quanto, também, conhecimentos, pertencentes a outras disciplinas foram ensinados sob o rótulo de Administração.

O currículo tal como o conhecimento atualmente não foi estabelecido, de uma vez por todas, em algum ponto privilegiado do passado. Ele esta em constante fluxo e transformação. De forma igualmente importante e relacionada, é preciso não interpretar o currículo como resultado de um processo evolutivo, de contínuo aperfeiçoamento em direção a formas melhores e mais adequadas. Uma análise histórica do currículo deveria, em vez disso, tentar captar as rupturas e disjunturas, surpreendendo, na história, não apenas aqueles pontos de continuidade e evolução, mas também as grandes descontinuidade e rupturas (SILVA, I995, p. 7).

Assim, o estudo sobre a história das disciplinas escolares e do currículo não consistem, simplesmente, em descrever como se organizava o conhecimento escolar no passado, apenas para mostrar como era diferente do atual, mas percorrer o conhecimento corporificado no currículo escolar como um artefato social e cultural, descrevendo a dinâmica social que moldou essa forma. As preocupações daqueles autores residem muito mais na compreensão dos fatores que levam à valorização de determinados conteúdos e métodos em detrimento de outros.

A dinâmica do currículo não é um processo meramente lógico e puro, tampouco internamente consistente e lógico, consistindo antes num amálgama de conhecimentos 'científicos', de crenças, de expectativas, assim, a história do currículo tentar descobrir quais os conhecimentos, valores e habilidades que eram considerados como verdadeiros e legítimos em 
uma determinada época, assim como tentar determinar de que forma essa validade e legitimidade foram estabelecidas (GOODSON, I995).

conforme Aires e Ern (2005), Goodson contempla o estudo do processo histórico de construção de uma disciplina escolar para além de explicitar as relações complexas entre a escola e a sociedade e de aceitar as disciplinas escolares como originárias, exclusivamente, do conhecimento acadêmico, mas está essencialmente interessado em entender como "o estatuto, os recursos e a estruturação das disciplinas escolares empurram o conhecimento da disciplina em direções específicas [...]” (GOODSON, I997, p. II8 apud AIRES; ERN, 2005, p. 3).

Em suma, a história do currículo não está centrada numa preocupação epistemológica com a verdade ou validade do conhecimento, mas voltada para os determinantes sociais e políticos do conhecimento educacionalmente organizado.

Mas fica a pergunta: O que é currículo? O currículo é originário da palavra latina currere. "Willian Pinar defendia que [...] currere significa correr - um verbo". Todavia, na educação, as interpretações tradicionais têm reduzido o termo à sua forma substantiva, "a pista - isto é, o plano de estudos" (KINCHELOE, 200I, p. I2).

O currículo, assim, acaba sendo compreendido com base em uma ruptura (PACHECO, 2002, p. I6): o currículo formal - como um plano precisamente delineado baseado em fins e finalidades; e, o informal - como um processo decorrente da aplicação do referido plano. Macedo (2006) concorda com essa redução e afirma:

Historicamente, poderíamos dizer que começamos a falar em currículo formal e currículo em ação como forma de contraposição à noção burocratizada das teorizações tradicionais do campo que acentuavam os documentos legais e as políticas institucionais como foco dos estudos do currículo (MACEDO, 2006, p. 100).

Essa ruptura também foi percebida por Goodson (I995, 200I, 2003) quando alertou para o perigo de somente estudar o currículo escrito, como se fosse um catálogo, ou, por outro lado, estudar somente a prática em sala de aula. Para o autor “a construção pré-activa pode estabelecer parâmetros 
importantes e significativos para a realização interactiva na sala de aula" (GOODSON, 200I, p. 55).

Sendo assim, o que está prescrito não é, necessariamente, o que é apreendido, e o que se planeja não é, necessariamente, o que acontece. Todavia, "[...] isto não implica que devamos abandonar nossos estudos sobre prescrição como formulação social, e adotar, de forma única, o prático. Pelo contrário, devemos estudar a construção social do currículo tanto em nível de prescrição como em nível de interação" (GOodson, 1995, p. 78).

O currículo escrito (dimensão pré-ativa) estabelece publicamente normas básicas que avaliam a prática ou com ela se relaciona, além de registrar as aspirações e objetivos da escolarização. Da mesma forma, a alocação de recursos financeiros fica vinculada a essas normas básicas sobre critérios de currículo. O currículo escrito é formado pelos desenhos curriculares propostos pelas instituições de ensino, por suas propostas pedagógicas, planejamento estratégico, programas de disciplina, dentre outros. Portanto, o estabelecimento de normas e critérios é relevante, mesmo quando a prática (currículo ativo) procura contradizer ou transcender a definição pré-ativa (GOODSON, 1995).

Em muitos momentos da vida acadêmica, o que está escrito não é praticado em sala de aula, mas ganha novos contornos, novas interpretações, criandose novas formas de currículo. Nesse sentido, busca-se atenuar o caráter prescritivo do sistema, ou seja, a proposição de que o currículo é um plano que "deve" ser aplicado ou executado na sala de aula, e estudar um currículo dinâmico em que:

[...] as teorias mantenham uma investigação sistemática sobre como se origina o currículo existente, como é reproduzido, como se transforma e responde a novas prescrições. Em síntese, uma teoria sobre como atuam, reagem e interagem as pessoas envolvidas na contínua produção e reprodução de currículo (GOODSON, 1995, p. 64).

Assim, o currículo ativo éformado pelas modalidades de ensino-aprendizagem, ou seja, uma ampla designação para um conjunto de atividades complexas que ocorrem no âmbito das disciplinas e visam proporcionar condições para a efetivação de experiências de aprendizagem pelos alunos. 
Envolvem estratégias e táticas utilizadas pelo professor e apresentam grande variabilidade e distintos níveis de abrangência, podendo ocorrer na forma mais comum - no interior de uma disciplina, interligando diferentes disciplinas - e como atividades extradisciplinares (no âmbito de uma área de concentração ou aplicação e interligando diferentes áreas) (FISCHER, I977, p. I29).

Esse conceito define tanto as estratégias, como as táticas dos professores, para desenvolver determinadas áreas de competência. Estruturam-se com base em conteúdos ou problemas do mundo real; são dimensionadas no espaço/tempo; envolvem o uso organizado de recursos humanos e materiais e têm como objetivo de proporcionar práticas de ensino que possibilitam o aprendizado de conteúdo e o desenvolvimento de competências conforme as possibilidades do aluno e as condições de desenvolvimento destas experiências (FISCHER, I977).

Se a aprendizagem é vista como resultado do processo de ensino, a avaliação é parte integrante desse processo. Sendo assim, além das modalidades de ensino-aprendizagem, a avaliação da aprendizagem é parte integrante do currículo interativo. Para Veiga (200I, p. I6I), avaliar, numa perspectiva de construção do conhecimento, "é efetivar oportunidades de ação-reflexão, num acompanhamento constante dos educadores, que levará o aluno a novas questões. A avaliação deixa de ser classificatória para ser diagnóstica”.

Não há, consequentemente, a necessidade de testar o que está escrito na prática da sala de aula, mas buscar entender como geralmente o currículo é produzido pelos professores, nas diferentes circunstâncias em que se encontram. A ligação entre a vida particular do professor e o currículo préativo e interativo possibilita insights com referência à estruturação e ação, determinando, assim, a construção do currículo (GOODSON, I995).

Além de refletir sobre os níveis de análise pré-ativa e interativa do currículo, também, é preciso entender os mecanismos de estabilidade e de mudança curriculares. Goodson (1995) defende uma análise que combine elementos dos fatores internos e externos às comunidades disciplinares. $\mathrm{O}$ entendimento do processo de construção social de uma determinada matéria escolar/disciplina exige a consideração de fatores internos e externos: 
Os fatores internos dizem respeito às condições de trabalho na própria área, tais como: o surgimento de diferentes grupos de liderança intelectual, a criação de centros acadêmicos de prestígio atuando na formação de seus profissionais, a organização de associações profissionais e a política editorial na área. Já os fatores externos estão relacionados à política educacional e aos contextos econômico social e político mais amplos (FERREIRA; MOREIRA, 200I, p. 5).

Refletindo sobre essa construção, percebe-se que os currículos dos cursos de pós-graduação em Administração no Brasil, num primeiro momento foram diretamente influenciados por fatores externos, em 1959, o Governo Federal instituiu o Programa de Ensino de Administração Pública e de Empresa (PBA-I) com objetivo de capacitar profissionais para o ensino de graduação em Administração. Esse programa tinha como metas: fornecer o serviço de professores norte-americanos para prestar assistência no que se refere à elaboração de currículos, métodos e técnicas de ensino, pesquisa e extensão; e, formar professores brasileiros para a preparação de alunos de nível médio e superior em Administração.

Assim, os professores formados por esse programa retornam às Instituições de Ensino Superior brasileiras para ensinar no curso de graduação em Administração, e, posteriormente, na década de 70, colaboram na criação dos currículos dos cursos de pós-graduação, com o apoio da Coordenação de Aperfeiçoamento de Ensino Superior (CAPES).

Após esse primeiro momento, a pós-graduação em Administração começa a receber influências de fatores internos, como da Associação Nacional de Pós-graduação e Pesquisa em Administração (ANPAD), fundada em 1976, dos primeiros centros de ensino (FGV, UfRGs, UFbA e UFMG) e dos primeiros periódicos da área (Revista de Administração da usp, criada em 1947, Cadernos de Administração Pública da EBAPE, em 1954; e, Revista de Administração de Empresas/FGv, em 196I).

Todavia, o peso dos fatores internos depende de três condições: da tradição da disciplina (prestígio acadêmico e tempo de existência), do nível de organização de seus profissionais (quer dizer, associações acadêmicas e publicações e política editorial da área) e das condições objetivas do lugar, 
tais como o seu regime político e a estrutura de seu sistema educacional (SANTOS, I990; FERreira; Moreira, 200I). Nesse sentido, Santos (I990) e Ferreira e Moreira (200I) formulam a hipótese de que quanto maior o nível de maturidade de uma disciplina e dos profissionais da área, maior será o peso dos fatores internos no seu desenvolvimento.

Essa relação é mais percepitível em uma disciplina como, por exemplo, matemática, que possui uma longa tradição. Não há como questionar o ensino da geometria ou a aritmética na área de matemática. Todavia, na Administração, percebe-se uma constante mudança de interesse de estudo de acordo com a incorporação de autores de outras áreas como Sociologia, Psicologia, Filosofia, Biologia, Educação, dentre outras.

Sendo a Administração um campo relativamente novo, cerca de 50 anos no Brasil, não há, ainda, uma tradição de ensino. O ensino foi regulamentado, em I950, com a criação do primeiro Curso de Administração na Fundação Getulio Vargas. A profissão foi regulamentada em 1965 (Lei de $n^{\circ}$ 4.769/65), mas, ainda, luta por sua consolidação no mercado de trabalho brasileiro, inclusive com proposições polêmicas, como a de reserva de mercado, por exemplo. Há uma lei tramitando no legislativo que solicita a comprovação do registro na respectiva Entidade de Fiscalização Profissional, para investidura em cargos, empregos ou funções na Administração Pública Direta, Indireta, Autárquica ou Fundacional, dos Poderes Executivo e Legislativo do Distrito Federal. Assim, é de se esperar que os fatores externos tenham maior peso no processo de construção e mudança do conhecimento, como, por exemplo, as diretrizes curriculares regulamentadas na graduação e a influência da política de avaliação dos Programas de Pós-Graduação da CAPEs.

Por outro lado, "o regime político, o nível e tipo de desenvolvimento de um país podem ter um grande peso no desenvolvimento de uma disciplina, tornando-a mais vulnerável aos fatores externos” (SANTOS, I990, p. 27), ou seja, "o peso dos fatores externos pode ser mais significativo em países que passam por processos acelerados de transformações" (FERREIRA; MOREIRA, 200I, p. 5).

Nesse sentido, os sistemas educacionais acabam produzindo padrões socialmente legítimos de professores, alunos, temas e atividades (GOODsON, 
1995). As comunidades disciplinares se apropriam desses padrões para a construção de retóricas que visam à obtenção de apoio ideológico e de recursos materiais dos grupos externos. Assim, ao mesmo tempo em que os sistemas educacionais limitam as comunidades disciplinares - que não são autônomas em suas decisões curriculares e profissionais -, também, promovem e sustentam determinadas visões sobre as disciplinas escolares. Quanto maior a capacidade de uma determinada retórica em associar interesses idealistas, materiais e morais, mais estabilizados e naturalizados estarão os discursos e as práticas curriculares.

Portanto, o currículo visto como uma construção social reflete padrões de status e hierarquias sociais existentes na sociedade global. Isto significa que, para se compreender o currículo ou o conhecimento, não basta estudar a esfera técnica em que ele é registrado - normas, leis, atas, programas, ementas, dentre outras -, é preciso, também, compreender a esfera social e política em que esse currículo ou conhecimento foi negociado. Dessa forma, a crítica realizada por Rocha (2003) de que o autor ressalta apenas os aspectos internos da escola para compreensão da dinâmica do currículo, não corresponde à amplitude da sua teorização, pois Goodson (1995) discutiu tanto os aspectos externos, como os aspectos internos na dinâmica do currículo.

No Brasil, na área de Administração, muitas pesquisas são organizadas com base no lançamento de editais de financiamento de pesquisa por organizações públicas federais e estaduais, como CNPQ, CAPES, Fundação de Amparo à Pesquisa do Estado da Bahia (FAPESB), dentre outras, e organizações estatais e privadas, por meio de suas fundações. Essas pesquisas geram publicações e, consequentemente, influenciam os conteúdos das disciplinas e currículos.

Finalizando, esta pesquisa foi fundamentada na ideia de que os currículos são reflexos de práticas sociais; sendo que currículo de um curso de formação profissional é:

[...] o conjunto de matérias, modos e meios de ensino aprendizagem, decorrentes do contexto cultural e da natureza do conhecimento envolvido, que assumam configurações de disciplinas e de articulações disciplinares, a 
serem desenvolvidas, cooperativamente, por professores e alunos, visando o desenvolvimento da competência socialmente desejável para o exercício de uma profissão (FISCHER, 200I, p. I30).

O conceito de currículo, neste caso, é muito mais compreensivo do que os conceitos das teorias tradicionais, já que abrange tanto modos e meios de ensino e aprendizagem, como, também, o desenho das disciplinas ou das articulações disciplinares, configurado em cursos de graduação e pós-graduação. Esses cursos oferecem tanto matérias de ensino que envolve uma série de conhecimentos limitados por um objetivo educacional, quanto atividades dentro ou fora da sala de aula, como formação docente (Capacitação Docente) e de orientação do trabalho acadêmico.

Após compreender os fatores temporais e espaciais que influenciam na construção do currículo ou disciplina, procura-se verificar, no próximo tópico, como o conhecimento se articulou nos currículos de pós-graduação de Administração.

\section{OS ESTUDOS ORGANIZACIONAIS NOS PROGRAMAS DE PÓS- GRADUAÇÃO STRICTO SENSU}

Para compreender o campo de Estudos Organizacionais nos cursos de pós-graduação de Administração é importante vislumbrar a construção dos currículos na graduação. Por longos anos, as matérias de ensino relacionadas aos EO foram ensinadas em diferentes cursos como Economia, Ciências Contábeis, Sociologia, dentre outras. A Administração nasce em berço interdisciplinar recebendo contribuições de diversas áreas com o objetivo de estudar as organizações.

Os currículos dos primeiros cursos de graduação em Administração no Brasil foram diretamente influenciados por fatores externos, isto é, pela política do governo federal que objetivava levar adiante o projeto de desenvolvimento nacional. Um passo marcante foi dado em 1959, quando o governo federal instituiu o Programa de Ensino de Administração Pública e de Empresa (PBA-I) com objetivo de capacitar profissionais para o ensino de graduação em Administração. Assinou-se, 
assim, um contrato de cooperação técnica internacional entre o governo brasileiro e norte americano que fornecia serviços dos professores norte-americanos para prestar assistência no que se refere à elaboração de currículos, métodos e técnicas de ensino, pesquisa e extensão. Além disso, o contrato previa apoio financeiro e técnico para formação de professores brasileiros para cursos de nível médio e superior de Administração. Vários professores aderiram ao programa e realizaram o mestrado nos Estados Unidos, que após formados, retornaram para as Instituições de Ensino Superior (IES) brasileiras para o ensino de graduação em Administração.

Bertero e Alcadipani (20I2) narram com base na pesquisa histórica a criação do curso de graduação em Administração na Fundação Getúlio Vargas (FGV), cujo currículo possuía um design inovador para a década de 1950 com predomínio das ciências sociais. Conforme os autores, nos dois primeiros anos, os alunos estudavam sociologia, psicologia, ciência política e a legislação brasileira (comercial, fiscal, tributária e trabalhista), além de disciplinas instrumentais à administração como contabilidade, matemática e estatística. A partir do segundo ano, os estudantes cursavam disciplinas específicas de administração, relacionadas às áreas tradicionais da administração, como contabilidade gerencial (managerial accounting), finanças, marketing, recursos humanos, produção e política de negócios (relacionada à estratégia). Conforme Bertero e Alcadipani (2012, p. 293), o programa era "calcado nos cursos de graduação norte-americanos da época e, possivelmente, da própria Michigan State University".

O curso de graduação da FGv foi um dos primeiros criados no Brasil e, possivelmente, o principal difusor deste currículo pelo país já que a Universidade Federal da Bahia (UfвA) e Universidade Federal do Rio Grande do Sul (UFRGs) também receberam cooperação técnica dos EUA para desenvolvimento dos seus cursos de graduação em Administração. Além disso, conforme Bertero e Alcadipani (2012), este design influenciou a construção do currículo mínimo (Parecer $\mathrm{n}^{\circ} 307$, de 08/07/1966, do Conselho Federal de Educação) estabelecido no Brasil 
para o bacharelado de administração. Os primeiros cursos de graduação em Administração não apresentavam uma disciplina específica sobre Teoria das Organizações, o conhecimento do campo de EO era discutido ao longo de disciplinas de áreas tradicionais da Administração.

Após uma década de ensino de graduação, a FGV oferece o primeiro curso de pós-graduação stricto sensu (mestrado) em administração (Tabela I).

Tabela I Cursos dos programas de pós-graduação stricto sensu em Administração no Brasil (1967 a 2007)

\begin{tabular}{|c|c|c|c|c|}
\hline \multirow[t]{2}{*}{ IES } & \multirow[t]{2}{*}{ Nome do Programa } & \multicolumn{3}{|c|}{ Ano de início } \\
\hline & & $\mathbf{M}$ & $\mathbf{F}$ & D \\
\hline FGV/RJ & Administração & 1967 & & 1997 \\
\hline USP & Controladoria e Contabilidade & 1970 & & 1978 \\
\hline PUC-RIO & Administração de Empresas & 1972 & & 1997 \\
\hline UFRGS & Administração & 1972 & & 1994 \\
\hline UFMG & Administração & 1973 & & 1995 \\
\hline UFRJ & Administração & 1973 & & 1976 \\
\hline FGV/SP & Administração de Empresas & 1974 & & 1976 \\
\hline UFLA & Administração & 1975 & & 2000 \\
\hline USP & Administração & 1975 & & 1975 \\
\hline UFPB/J.P. & Administração & 1976 & & \\
\hline UnB & Administração & 1976 & & 2006 \\
\hline $\mathrm{PUC} / \mathrm{SP}$ & Administração & 1978 & & \\
\hline $\mathrm{PUC} / \mathrm{SP}$ & Ciências Contábeis e Atuariais & 1978 & & \\
\hline UFRN & Administração & 1978 & & 2006 \\
\hline UFSC & Administração & 1978 & & 1995 \\
\hline UFBA & Administração & 1983 & & 1993 \\
\hline FGV/SP & Administração Pública e Governo & 1990 & & 2002 \\
\hline UFPR & Administração & 1992 & & 2004 \\
\hline UNESA & Administração e Des. Empresarial & & 1994 & \\
\hline FJP & Administração Pública & 1995 & & \\
\hline UFPE & Administração & 1995 & & 2000 \\
\hline UNIFOR & Administração de Empresas & 1995 & & \\
\hline FURB & Administração & 1997 & & \\
\hline UNIVALI & Turismo e Hotelaria & 1997 & & \\
\hline
\end{tabular}




\begin{tabular}{|c|c|c|c|c|}
\hline \multirow[t]{2}{*}{ IES } & \multirow{2}{*}{ Nome do Programa } & \multicolumn{3}{|c|}{ Ano de início } \\
\hline & & $\mathbf{M}$ & $\mathbf{F}$ & D \\
\hline UFRJ & Ciências Contábeis & 1998 & & \\
\hline PUC/RS & Administração e Negócios & & 1998 & \\
\hline UniFECAP & Ciências Contábeis & 1999 & & \\
\hline UPM & Administração de Empresas & 1999 & & 2003 \\
\hline IBMEC & Administração & & 1999 & \\
\hline PUC/PR & Administração & 2000 & & 2006 \\
\hline UCS & Turismo & 2000 & & \\
\hline UEM & Administração - UEM/UEL & 2000 & & \\
\hline UFES & Administração & 2000 & & \\
\hline UnB & Ciências Contábeis & 2000 & & 2007 \\
\hline UNIFACS & Administração Estratégica & 2000 & & \\
\hline UNISANTOS & Gestão de Negócios & 2000 & & \\
\hline UNISINOS & Administração & 2000 & & \\
\hline UNISINOS & Ciências Contábeis & 2000 & & \\
\hline FPL & Administração & & 2000 & \\
\hline PUC/MG & Administração & & 2000 & \\
\hline UFRJ & Gestão e Estratégia em Negócios & & 2000 & \\
\hline FAM & Hospitalidade & 2001 & & \\
\hline FUCAPE & Ciências Contábeis & & 2001 & \\
\hline UFC & Controladoria & & 2002 & \\
\hline IMES & Administração & 2003 & & \\
\hline UFRPE & Administração e Des. Rural & 2003 & & \\
\hline UFSM & Administração & 2003 & & \\
\hline UFU & Administração & 2003 & & \\
\hline UNIVALI & Administração & 2003 & & 2007 \\
\hline FEAD & Administração & & 2003 & \\
\hline UNINOVE & Administração & 2006 & & \\
\hline
\end{tabular}

Legenda: $M$ - Mestrado, D - Doutorado, F - Profissionalizante.

Fonte: Elaborada com base nas informações pesquisadas na CAPEs/ MEC em 10/08/2007.

A partir da década de 1970 vários cursos de mestrados são criados no país e diferentemente do engessamento curricular dos cursos de graduação (FISCHER, 1993), os currículos dos cursos de pós-graduação não tiveram uma 
regulação do Ministério da Educação, no sentido de propor um currículo mínimo ou disciplinas obrigatórias. O primeiro mestrado data de 1967 e foi ofertado na área de Administração Pública, pela Escola do Rio de Janeiro/ FGV. Em 1970, foram criados os mestrados em Controladoria e Contabilidade da usp e, em 1972, o de Administração de Empresas na PUC-RJ. Ainda na década de 1970, várias outras iniciativas se seguiram: UFRGS, UFRJ, FGV/sP, Universidade Federal de Lavras (UfLA), usp, Universidade Federal de Paraíba (UfPB/JP), unB, PUC/sp, Universidade Federal do Rio Grande do Norte (UfRN) e USFC. Dessa forma, 15 cursos de mestrado foram criados ao longo da década de 1970.

No nível de doutorado, os primeiros cursos foram oferecidos em meados dos anos setenta; em 1975, pela Faculdade de Economia e Administração da USP, na área de Administração em geral, em parceria com a Federação das Indústrias e a Associação do Comércio de São Paulo; e, em 1976, pela Escola de Administração de Empresas de São Paulo/FGV, na área de Administração de empresas. Um ano depois foi criado o primeiro doutorado em Administração Pública pela FGv/RJ. Observa-se que os cursos de doutorado foram ofertados somente após ir anos de funcionamento dos cursos de pós-graduação stricto sensu. Bertero (2006) ressalta que a maioria dos programas mostrou mais cautela em oferecer esses cursos.

O campo de Estudos Organizacionais na pós-graduação surgiu em meio à discussão da crítica da importação do modelo americano na década de 1970. Mesmo assim, os primeiros cursos de mestrado (Tabela I) foram fortemente influenciados pelas matrizes curriculares norte-americanas, visto que os professores daquele, pois aqui instalados colaboraram também para organização desses currículos e lecionaram disciplinas nos primeiros anos dos cursos. Além da docência de norte-americanos nos cursos de pós-graduação brasileiros, muitos professores brasileiros incentivados pelo programa de capacitação de docentes (com bolsas de pós-graduação) da Coordenação de Aperfeiçoamento de Pessoal de Nível Superior (Capes), viajaram para o exterior para empreender seus mestrados e doutorados. Diferente da primeira leva que priorizou os estados norte-americanos, esses professores viajam para outros países da Europa como França, Canadá e 
Inglaterra. Somente com o retorno desses professores (FISCHER, 2003), na década de 1980, uma mudança interna nas disciplinas pôde ser verificada, com base na incorporação de assuntos mais críticos e uma bibliografia francófona. As disciplinas dos cursos de pós-graduação foram influenciadas diretamente pela "escola de Frankfurt, Michael Foucault, e os textos de Guerreiro Ramos foram usados em substituição aos manuais anteriores, em algumas disciplinas que mantinham o rótulo antigo e a mesma posição nos eixos curriculares” (FISCHER, 2003a, p. 53). As pesquisas dos núcleos com acento na realidade regional e nacional refletiam a inclusão de tópicos de conteúdos e bibliografia mais atualizados.

Uma pesquisa realizada por Alves e Reinert (2006) sobre a multidisciplinaridade no Curso de Graduação em Administração, da Universidade de Santa Catarina, mostrou que o elenco de disciplinas básicas oferecidas por outros departamentos - matemática, psicologia, filosofia, sociologia, direito - no curso, baixou de $66,1 \%$ do total do currículo, em 1978, para 34,1\%, em 2004. Para os autores, esse resultado afere diminuição da multidisciplinaridade do curso. Todavia, uma nova leitura desse resultado poderia ser realizada. Essa queda da participação de outros departamentos pode indicar a consolidação da área de Administração enquanto campo de conhecimento, revelando a incorporação do conteúdo dessas outras áreas pela própria Administração e a interdisciplinaridade do conhecimento. Com a criação de disciplinas como Administração I e Teoria Geral da Administração, os conteúdos multidisciplinares e paradigmas de outras áreas do conhecimento são discutidos no próprio domínio da Administração. Essa dinâmica pode explicar a incorporação/absorção de uma série de debates dos Estudos Organizacionais Contemporâneos (cultura organizacional, abordagens cognitivistas etc.).

Um exemplo dessa incorporação foi dado por Serva e Jaime Jr. (2002), quando descreveram a aproximação entre a administração e antropologia por um estudo histórico das correntes/escolas de Administração. A antropologia influenciou a Escola de Relações Humanas, que fomentou o Comportamento Organizacional, que se desdobrou em Desenvolvimento Organizacional e, finalmente, originou a Cultura Organizacional, todas 
essas correntes na área de Administração. Os autores, ainda, afirmam que não encontraram estudos sobre organizações na área de Antropologia, somente a partir de I990, provavelmente influenciados pelo debate na Administração.

Além das influências externas à área de Administração, a pós-graduação em Administração também recebeu influências internas como a criação, em 1976, da Associação Nacional de Pós-Graduação e pesquisa em Administração (ANPAD), o fortalecimento dos primeiros centros de ensino e pesquisa (FGV, UFRGS, UFBA, UFMG) e a criação e consolidação dos primeiros periódicos na área (Revista de Administração da USP em I947, Cadernos de Administração Pública da EBAPE em 1954; Revista de Administração de Empresas/FGV Em I96I).

Todavia, o peso desses fatores depende de três condições: da tradição da disciplina (prestígio acadêmico e tempo de existência), do nível de organização de seus profissionais (quer dizer, associações acadêmicas e publicações e política editorial da área, no caso da Administração, tem-se o Conselho Regional de Administração) e das condições objetivas do lugar, tais como o regime político e a estrutura do sistema educacional. Santos (1990) e Ferreira e Moreira (200I) formulam a hipótese de que quanto maior o nível de maturidade de uma disciplina e dos profissionais da área, maior será o peso dos fatores internos no seu desenvolvimento.

Sendo a Administração um campo de ensino relativamente novo, cerca de 50 anos no Brasil, e interdisciplinar, não há ainda uma tradição de ensino. O ensino foi regulamentado em 1950, com a criação do primeiro Curso de Administração na Fundação Getúlio Vargas. A profissão foi regulamentada em I965 (Lei n. 4.769/65), mas ainda luta por sua consolidação no mercado de trabalho brasileiro, inclusive com proposições polêmicas como, por exemplo, a proposta de reserva de mercado da lei que tramita pelo legislativo que solicita a comprovação do registro na respectiva Entidade de Fiscalização Profissional, para investidura em cargos, empregos ou funções na Administração Pública Direta, Indireta, Autárquica ou Fundacional, dos Poderes Executivo e Legislativo do Distrito Federal. Assim, é de se esperar que os fatores externos - como as diretrizes curriculares regulamentadas 
na graduação ou a influência da política de avaliação dos Programas de Pós-Graduação da CAPES - tenham maior peso no processo de construção e mudança do conhecimento.

Bertero et al. (2013) em acordo com Goodson (1995) alertam para o papel dos sistemas educacionais na produção de padrões socialmente legítimos de professores, alunos, temas e atividades. As comunidades disciplinares se apropriam desses padrões para a construção de retóricas que visam à obtenção de apoio ideológico e de recursos materiais (inclusive financeiros) dos grupos externos. Assim, ao mesmo tempo em que os sistemas educacionais limitam as comunidades disciplinares, que não são autônomas em suas decisões curriculares e profissionais, também promovem e sustentam determinadas visões sobre as disciplinas escolares. Quanto maior a capacidade de uma determinada retórica em associar interesses idealistas, materiais e morais, mais estabilizados e naturalizados estarão os discursos e as práticas curriculares.

No Brasil, na área de Administração, muitas pesquisas são organizadas com base no lançamento de editais de financiamento de pesquisa por organizações públicas federais e estaduais como o Conselho Nacional de Desenvolvimento Científico e Tecnológico (CNPQ), CAPEs, Fundação de Amparo à Pesquisa do Estado da Bahia (FAPESB), dentre outras, ou organizações estatais e privadas por meio de suas fundações. Essas pesquisas significam apoio financeiro para realização e manutenção das atividades educacionais nas Instituições de Ensino, que se transformam em publicações, e, consequentemente, retornam para a academia influenciando, posterior e novamente, os conteúdos que são selecionados pelos docentes da pós-graduação.

Em artigo publicado por Bertero et al. (2013), Alexandre Faria revela que várias instituições transnacionais e um extraordinário número de think tanks passaram a ser um dos mais poderosos produtores, legitimadores, classificadores e difusores de conhecimento (no singular) em escala global. Assim, atualmente, a produção de conhecimento que posteriormente é ensinada em sala de aula delineia-se fortemente influenciada por padrões do mundo euro-americano. Portanto, o currículo, visto como uma 
construção social espelha padrões de status e hierarquias sociais existentes na sociedade global. Isto significa que para se compreender o currículo ou o conhecimento, não basta estudar a esfera técnica em que ele é registrado (normas, leis, atas, programas, ementas, dentre outras), mas é preciso também compreender a esfera social e política em que esse currículo ou conhecimento foi negociado. 


\section{PROCEDIMENTOS METODOLÓGICOS}

A pesquisa fundamentou-se na abordagem qualitativa, pois buscou a descrição e interpretação do ensino no campo de Estudos Organizacionais nas instituições de pós-graduação stricto sensu brasileiras que oferecem cursos de Administração. A investigação foi realizada por meio de uma pesquisa exploratória e descritiva que tem "como principal finalidade desenvolver, esclarecer e modificar conceitos e ideias, tendo em vista, a formulação dos problemas mais precisos ou hipóteses pesquisáveis para estudos posteriores" (GIL, 2006, p. 43). Assim, o processo de análise e de interpretação foi interativo, pois se elaborou pouco a pouco a explicação lógica do fenômeno estudado, examinado as unidades de sentido, as interrelações entre essas unidades e entre as categorias em que elas se encontram reunidas.

O objeto empírico da pesquisa foi o campo de Estudos Organizacionais, ensinado com base nos currículos dos Cursos de Pós-Graduação Stricto Sensu em Administração, no Brasil (mestrado e doutorado acadêmicos). Foram selecionados nove programas de pós-graduação na área de Administração: Fundação Getúlio Vargas (FGV/RJ), Fundação Getúlio Vargas (FGV/SP), Universidade Federal da Bahia (UFBA), Universidade Federal de minas Gerais (UfMG), Universidade Federal de Pernambuco (UFPE), Universidade Federal do Paraná (UfPR), Universidade Federal do Rio Grande do Sul (UfRgs), Universidade Federal de Santa Catarina (UFSC) e Universidade de Brasília (UNB), por causa de sua relevância histórica, foram os primeiros cursos de Administração criados no país, oferecem mestrado e doutorado acadêmicos e seus docentes são representativos do campo de Estudos Organizacionais. Os professores entrevistados ensinam ou ensinaram a disciplina Teoria das Organizações ou Estudos Organizacionais na pós-graduação stricto sensu nas instituições selecionadas para o estudo.

A coleta de informações se deu por meio de: I) levantamento bibliográfico de dados já sistematizados em publicações anteriores, para compreender a trajetória do ensino. Foram selecionados artigos nos principais periódicos do Qualis CAPES e alguns eventos da área. 2) pesquisa documental se deu 
nos Relatórios da Memória da Pós-Graduação, Sistema Lattes e legislação na CAPES, INEP e MEC, no ano de 2008 , além da análise dos programas das disciplinas dos professores entrevistados e dos currículos dos cursos de mestrado e doutorado selecionados. 3) entrevistas semiestruturadas com dezessete professores dos cursos estudados que lecionam(ram) disciplinas no campo de EO em 2008. As entrevistas duraram em média uma hora e foram transcritas e posteriormente digitadas e editadas.

A análise das informações se deu pela técnica de análise de conteúdo (BARDIN, 1977). Foram criadas Unidades de Análise dentro de Componentes que influenciam o ensino dos EO nos programas de pós-graduação. Cada Componente foi classificado segundo a sua dimensão temporal e espacial. Assim, foram construídos os seguintes componentes com respectivas unidades de análise: Fatores externos às comunidades disciplinares: Política Educacional (legislação Federal) e Contexto social, político e econômico (documentos). Fatores internos às comunidades disciplinares: Dimensão pré-ativa - Design curricular (disciplinas, atividades), Planejamento do ensino (Objetivo do ensino, Conteúdo do ensino, Método de ensino) e Representação do conhecimento para ensino (Estudos Organizacionais); Dimensão Interativa - Prática em sala de aula (Modalidades de ensinoaprendizagem e processo de avaliação do ensino-aprendizagem).

A próxima sessão apresenta os resultados da análise das informações pesquisadas, descrevendo os EO como matéria de ensino e debatendo os desafios para sua consolidação.

\section{OS ESTUDOS ORGANIZACIONAIS COMO MATÉRIA DE ENSINO: CAMPO CONSTRUÍDO BASEADO EM DIFERENTES PERCEPÇÕES}

Neste trabalho, embora o termo Teoria das Organizações seja ainda mais utilizado na academia, utiliza-se 'Estudos Organizacionais' por se tratar de "uma confluência de diversas disciplinas, suportadas por paradigmas distintos, para a qual contribuem, especialmente, as disciplinas de Ciências Sociais como: Sociologia, Ciência Política, Antropologia, Psicologia, História e Economia” (FISCHER, 2003, p. 50) que tem o objetivo de estudar as organizações. 
As Ciências Sociais foram a base mais sólida para o desenvolvimento de estudos no campo (CHANLAT, 1999). Todavia, os EO se consolidaram recebendo contribuições de várias áreas do conhecimento. Fischer (200I, p. I28) explica que:

[...] a economia foi a disciplina determinante no final do século XIX e em grande parte do século xx, sendo substituída em parte pela Sociologia e Psicologia a partir dos anos 30 até a implosão dos anos 80, quando a Antropologia e Ciência Política afirmaram-se pelas contribuições aos estudos de cultura organizacional ou estudos sobre poder e as instituições.

O campo passa por uma ruptura paradigmática a partir da década de 90 e desenvolve-se em três direções: "a afirmação de campos de saber interdisciplinares como a Psicossociologia; o uso de abordagens interdisciplinares para temas como: cognição, cultura, gênero, estratégia e tecnologia; e, a tentativa de encontrar uma nova disciplina de síntese" (FISCHER, 200I, p. I29).

Vive-se nesta última década uma construção heterogênea do campo, com influência da antropologia, ciência política, ciências sociais, economia, psicologia, dentre outras e uma intensa discussão sobre a sua consolidação (BERTERo et al., 2013). Desta forma, o campo de EO é interdisciplinar, construído com base na imersão em outras disciplinas para compreensão da organização. Essa interdisciplinaridade enriquece a análise, mas também dificulta um consenso sobre o campo. Mas fica a pergunta: seria uma disciplina, por mais flexível que fosse as suas fronteiras ou mais integradora de outros campos do saber, capaz de articular os diversos corredores do conhecimento em Ciências Sociais? (FISCHER, 200I).

Os desenhos curriculares dos Programas de Pós-Graduação Stricto Sensu em Administração analisados mostram que o campo de EO se estabelece como uma disciplina obrigatória na formação do pós-graduado em Administração (Quadro I). 
Quadro I Disciplinas obrigatórias dos programas de pós-graduação em Administração stricto sensu

\begin{tabular}{|c|c|c|}
\hline Programa & Mestrado & Doutorado \\
\hline FGV/RJ & Teoria das Organizações & $\begin{array}{l}\text { Pensamento Administrativo Contemporâneo I } \\
\text { Pensamento Administrativo Contemporâneo II }\end{array}$ \\
\hline PUC/RJ & Teoria Geral de Administração & Teoria Geral de Administração \\
\hline UFRGS & $\begin{array}{l}\text { Teoria das Organizações } \\
\text { Análise Organizacional }\end{array}$ & Teoria das Organizações: estudos avançados \\
\hline UFMG & Evolução das Teorias das Organizações & Teoria Organizacional Avançada \\
\hline UFRJ & Teoria das Organizações & \\
\hline $\mathrm{FGV} / \mathrm{SP}$ & Teoria das Organizações & Teoria das Organizações \\
\hline UFLA & Teoria das Organizações & Teoria das Organizações \\
\hline \multicolumn{3}{|l|}{ USP } \\
\hline UNB & Teorias das Organizações & Teoria das Organizações \\
\hline UFRN & Teorias das Organizações & Teoria das Organizações \\
\hline UFSC & Teoria das Organizações & Estudos Organizacionais Contemporâneos \\
\hline UFBA & Estudos Organizacionais & Tópicos especiais em Estudos Organizacionais \\
\hline FGV/SP* & - & - \\
\hline UFPR & Teoria das Organizações & Tópicos especiais em Doutorado \\
\hline UFPE & Teorias Organizacionais & $\begin{array}{l}\text { Tópicos Avançados em Estudos } \\
\text { Organizacionais }\end{array}$ \\
\hline UPM & Estudos e Análise Organizacional & - \\
\hline PUC/PR & Teorias das Organizações & Teoria das Organizações \\
\hline UNIVALI & Teorias das Organizações & Estudos Organizacionais Contemporâneos \\
\hline \multicolumn{3}{|c|}{ Nota: ${ }^{*}$ Curso de Administração Pública e Governo. } \\
\hline
\end{tabular}

Verifica-se que dos i8 programas avaliados somente dois não ofereciam uma disciplina sobre EO. Na pós-graduação, o campo de EO se desenvolveu baseado em múltiplas nomenclaturas e possibilidades, sempre dependendo do corpo docente da instituição de ensino e suas propostas de pesquisa. Um levantamento realizado, em 2006, nos currículos dos cursos de pós-graduação mostrou que a nomenclatura segue a denominação dada na graduação, sendo a mais utilizada a Teoria das Organizações. Todavia, o nome Estudos Organizacionais já aparece no programa da UFBA, UPM e UFSC (Quadro I). 
Nesses programas (mestrado e doutorado) os alunos cursam disciplinas ligadas à metodologia ou pesquisa e aos Estudos Organizacionais. Dois programas inseriram uma disciplina sobre conhecimento ou epistemologia e uma sobre ensino. Nas disciplinas obrigatórias, os docentes acabam seguindo uma estrutura mais padronizada de conhecimento, pois há uma realidade socialmente construída de que o estudante "deveria" conhecer sobre EO. Como afirmou o professor entrevistado 7 :

[...] tenho dois elementos que norteiam a montagem das disciplinas [...]. De um lado aquilo que eu considero, gostando ou não, tendo interesse pessoal ou não, [...], tem que ser dado. Tem que ser discutido, tem que ser estudado, porque não se pode fazer pós-graduação sem estudar sobre poder nas organizações, teoria estruturalista, perspectiva crítica, teoria da contingência. Não tenho interesse nenhum em teoria da contingência, mas não posso deixar de discutir em sala de aula, até porque o que se estuda sobre estruturalismo na graduação é muito pouco, então, por mais que eu possa gostar ou não, não importa, tem que ser dado.

A maioria dos professores entrevistados afirmou que ensina diferentes linhas de pensamento sobre as organizações e gestão, independentemente do seu interesse sobre o assunto. Além da disciplina obrigatória, os programas possuem disciplinas eletivas para formação do estudante. As disciplinas eletivas podem ser tanto oferecidas por linhas/núcleos de pesquisa (tendência mais recente dos programas organizarem as disciplinas por linha de pesquisa) ou pela construção do estudante com seu orientador de forma mais ampla. O Quadro 2 apresenta as disciplinas relacionadas ao campo de EO: 
Quadro 2 Exemplos de disciplinas eletivas dos Mestrados e Doutorados Acadêmicos (2008)

\begin{tabular}{|c|c|}
\hline EAESP & $\begin{array}{l}\text { - Administração Intercultural } \\
\text { - Análise Institucional de Organizações } \\
\text { - Comportamento Organizacional } \\
\text { - Comunicação e Didática } \\
\text { - Estudos Organizacionais no Brasil } \\
\text { - Organizações Pós-Industriais } \\
\text { - Teoria Crítica em Estudos Organizacionais }\end{array}$ \\
\hline UFMG & $\begin{array}{l}\text { - Poder e Organização } \\
\text { - Cultura, Identidade e Simbolismo nas Organizações } \\
\text { - Gestão Pública no Estado Contemporâneo } \\
\text { - Tomada de Decisão: Teoria e Processo } \\
\text { - Comportamento Humano nas Organizações } \\
\text { - Mudança Organizacional } \\
\text { - Análise Qualitativa nas Organizações } \\
\text { - Teoria da Administração Pública }\end{array}$ \\
\hline UFPR & $\begin{array}{l}\text { - Administração Estratégia } \\
\text { - Comportamento Organizacional } \\
\text { - Estratégias de Internacionalização } \\
\text { - Economia do Poder, Estado e Sociedade } \\
\text { - Teorias da Decisão } \\
\text { - Análise Institucional de Organizações } \\
\text { - Empreendedorismo e Gestão Estratégica de Pequenas Empresas } \\
\text { - Dinâmica de Sistemas Aplicada a Estudos Organizacionais } \\
\text { - Cultura, Aprendizagem e Conhecimento Organizacional } \\
\text { - Redes e Relações Intra e Interorganizacionais }\end{array}$ \\
\hline UFRGS & $\begin{array}{l}\text { - Conhecimento em Administração } \\
\text { - Sociologia do Trabalho } \\
\text { - Antropologia na Administração } \\
\text { - Comportamento Organizacional: Trabalho, Gestão e Subjetividade } \\
\text { - Aprendizagem em Administração e Competências: Conceitos e Práticas } \\
\text { - Aprendizagem Organizacional: Processos Formais e Informais } \\
\text { - Evolução das Teorias de Liderança } \\
\text { - Negócios Internacionais } \\
\text { - Conhecimento em Administração } \\
\text { - Introdução À Filosofia da Ciência }\end{array}$ \\
\hline
\end{tabular}

Fonte: Elaborado com base nas páginas institucionais dos Programas disponível na internet ou no manual dos Estudantes

O Quadro 2 exemplifica disciplinas eletivas ou optativas de quatro programas estudados, relacionadas com as linhas de pesquisa sobre Estudos Organizacionais. O campo é representado, nessa oferta, por uma série de disciplinas organizadas com base em temas transversais ou pontuais (poder, cultura, estrutura etc.), teorias organizacionais específicas (Teoria Institucional, Teoria Sistêmica etc.), recortes paradigmáticos (Teoria Crítica, 
Simbolismo etc.), assuntos reflexivos relacionados à formação específica do professor (ensino) e relacionados à formação do pesquisador (como pesquisa qualitativa), dentre outras.

Como já foi ressaltado, o campo absorve vários tipos de conhecimentos reflexivos aos Estudos Organizacionais e comporta-se como um campo crítico. Dificilmente, uma disciplina conseguiria envolver todos os assuntos que são temas de interesses dos docentes e pesquisadores. Dessa forma, os programas inserem uma disciplina obrigatória que busca discutir a amplitude do conhecimento do campo e oferece disciplinas eletivas e optativas sobre temas específicos relacionados ao interesse de pesquisa e formação dos docentes, quando estes têm maior liberdade de discutir assuntos relacionados com suas pesquisas e produção acadêmica.

Com base nessa representação pré-ativa dos currículos, buscou-se compreender a dimensão interativa, com base nos docentes. O campo de Estudos Organizacionais que se representa é aquele que se entende enquanto comunidade científica e acadêmica. Assim, os docentes podem afirmar qualquer coisa que queiram sobre Estudos Organizacionais, mas essa afirmação não se torna realidade até que seja socialmente aceita, isto é, orientadores de trabalhos acadêmicos, editores, revisores, estudantes, leitores e conferencistas, também, devem "ver" a realidade como esta se apresenta para os docentes.

Assim, o que são os Estudos Organizacionais enquanto campo de ensino?

Não há entre os professores uma definição única para o que venha a ser os Estudos Organizacionais, a maior parte dos entrevistados atribui a ideia de uma área ou campo ou conjunto de estudos sobre organizações e vida organizada. Essa pluralidade de percepções é um desafio para o campo, mas como afirma Clegg e Hardy (1998, p. 37) "é a luta entre as diferentes abordagens e com base na diversidade e na ambiguidade de significado que aprendemos; não é pela recitação de uma presumível uniformidade, consenso e unidade, submetidos a uma forma que exija aceitação inquestionável”. Isso impacta na configuração dos currículos e nas ofertas de disciplinas nos cursos de Administração, consequentemente, 
a seleção de assuntos das disciplinas obrigatórias é diversificada, pois não há um consenso a respeito do que ministrar.

Com base na fala dos entrevistados, é mais adequado chamar o campo como "uma série de conversações [...] que ajudam a construir organizações por meio de termos derivados de paradigmas, métodos e suposições, todos decorrentes de conversações prévias" 21998, p. 30). Conversações estas que foram construídas na área de Economia, na Sociologia, na Psicologia, na Antropologia e na Ciência Política que foram incorporadas aos EO, com base em interpretações de pesquisadores, tornando a análise das organizações mais complexa. Assim, a tentativa de encontrar nova disciplina de síntese, como a Antropologia (FISCHER, 200I), para os EO parece ser impossível, já que uma disciplina por mais ampla que seja para abarcar os diversos interesses dos docentes e pesquisadores brasileiros do campo de EO não conseguirá abarcar os interesses de pesquisa e perspectiva paradigmática dos núcleos de influência do campo.

Essa interdisciplinaridade se por um lado enriquece a análise, por outro, dificulta um consenso sobre o campo. Basicamente, os EO são uma construção de mais de uma disciplina, desde a sua origem. Como visto, o estudo das organizações foi recortado com base em diversas visões, seja econômica, psicológica, sociológica etc. Cada uma dessas visões, ao longo do tempo, contribuiu para a construção do conhecimento e deixou marcas para a representação que se tem neste momento. A partir de 1990, há uma distinta aproximação de duas ou mais disciplinas, ou seja, inicia-se uma tentativa de quebrar a incomensurabilidade2 dos paradigmas, no sentido de compreender as organizações. Contudo, essa postura contranormal gera conflitos e rupturas dentro da comunidade acadêmica, deixando a discussão acalorada em eventos acadêmicos (BERTERo et al., 20I3).

Conforme o entrevistado 15 , o campo de EO passou por muitas mudanças. A década de 1990 é marcada pela ruptura do funcionalismo: “[...] a principal mudança foi a primeira grande ruptura, a ruptura do funcionalismo tradicional com incursões. Digamos assim, um funcionalismo em transformação, agregando outras vertentes como o estudo de cultura, num 
viés Hofesdetiano ${ }^{\mathrm{I}}$, Schein e tal; os estudos de aprendizagem, os estudos de estratégia". Ainda segundo o entrevistado 15 , houve uma dissidência do funcionalismo tradicional, uma vertente chamada de "estudos radicais críticos". Por fim, o entrevistado i5 ressalta uma vertente que chamou de "pós-moderno difuso", "eu acho que agora nós estamos aí no que seria um momento de construção paradigmática com base em práticas nacionais, internacionais e locais, embora haja uma preocupação de globalizar a produção, de internacionalizar a produção" (ENTREVISTADO I5).

Neste momento, o local ganha uma importância muito grande no Brasil, baseado no momento em que os pesquisadores discutem o que publicar no contexto internacional. É uma revalorização da cultura local que, desde a década de 1970, foi alertada por Maurício Tragtenberg, Fernando Prestes Motta e Guerreiro Ramos. O entrevistado I2 exemplifica como tenta inovar nos EO:

Eu percebi que estava no mesmo caminho repetido e estou tentando mudar, fazer uma coisa diferente. Tenho trabalhado de uma forma distinta, por exemplo, agora analiso primeiro o problema, um problema da nossa realidade, local, no Estado do Rio, na América Latina ou no estado que moro, e com base no problema vou buscar a história para compreender melhor e solucionar, que é uma forma diferente de trabalhar. A gente tem opções teóricas e as práticas. O que a gente pode imaginar para resolver aquele problema, claro que sempre isso dentro de pressupostos ontológicos, epistemológicos, depende muito do trabalho para você escolher determinado tipo de teoria, mas vai escolher aquela que está dentro da nossa visão de mundo; há diferentes possibilidades teóricas, e ela tem que ser uma teoria que se adapte à solução de um determinado problema.

O professor entrevistado diferente de discutir teorias e paradigmas em sala de aula, parte da escolha do problema da realidade local para assim selecionar a teoria que será utilizada para a análise, levando em conta a sua visão de mundo. Para o entrevistado 3, pesquisador da área de comportamento organizacional, a principal mudanças nos EO: \begin{tabular}{l}
\hline 1 Relacionado com os estudos sobre cultura organizacional, realizados por \\
Geert Hofestede.
\end{tabular} 
Nesse meu campo de estudos micro-organizacionais, acho que há uma grande mudança que é essa revolução sócio-cognitivista ou sócio-construtivista. Eu acho que isso é um aporte teórico que chegou com uma força muito grande, isso tem impactado fortemente a pesquisa na área do comportamento organizacional. Eu acho que tem reflexos, inclusive, para as teorias macroorganizacionais. Por exemplo, hoje, ninguém ainda imagina a organização como uma entidade, um ser que toma decisões, mas são pessoas; e, entender as pessoas é uma coisa importante, fundamental para entender a dinâmica, os processos, as estruturas, [...] essa revolução sócio-construtivista que vem com a cognição, com o avanço da teoria do conhecimento vem aproximando os mundos, você vai lá para uma perspectiva institucionalista.

O dissenso sobre a percepção dos Estudos Organizacionais gera rupturas e defesas de pontos de vistas. Essa defesa de pontos de vistas se agrega em criar campos contestados de produção e ensino. Refletindo sobre isso, o que é ensinado nas disciplinas obrigatórias dos mestrados acadêmicos sobre Estudos Organizacionais? O Quadro 3 traz consensos sobre os temas que se repetiram nos Planos de Ensino. Não há um limite nesses recortes, eles se transpõem nas propostas dos docentes.

Quadro 3 Temas de ensino que se repetem nos Planos de Ensino

\begin{tabular}{|llll|}
\hline Teorias & Temas & & Escola/Perspectivas \\
\hline Estruturalismo, pós-estruturalismo & Conflito & Indivíduo & Escola Crítica \\
\hline Teoria da Burocracia & Controle & Poder & Escola Funcionalista \\
\hline Teoria dos Sistemas & Cultura & $\begin{array}{l}\text { Processo } \\
\text { decisório }\end{array}$ & Escola Interpretacionista \\
\hline Contingencialismo & Dominação & & Perspectiva Brasileira \\
\hline Institucionalismo e neo-institucionalismo & Estrutura & \\
\hline
\end{tabular}

Fonte: Elaborado com base nos Planos de Ensino

De maneira geral, verificaram-se três formas preponderantes de organizar o conhecimento nesses programas: com base em uma evolução histórica (paradigmas ou escolas) e reflexões de interesse (exemplo: Plano de Ensino I), por meio das Escolas e temas transversais (exemplo: 
Plano de Ensino 2) e por meio de um diálogo com as diferentes ciências (exemplo: Plano de Ensino 3).

Presumindo que os desenhos curriculares dos cursos de pós-graduação possuem um efeito mimético como os da graduação (FISCHER, 2003), a discussão dessas três formas de organização do conhecimento sobre os EO nos Planos de Ensino (mestrados) abarcam as demais seis configurações que seguem praticamente os mesmos conteúdos.

No Plano de Ensino I (Figura I), o docente selecionou e organizou o conhecimento com base em "uma abordagem histórica, eu digo histórica da área, então, você percorre as várias teorias, mais ou menos talvez numa ordem cronológica, e pode haver também uma abordagem mais tópica. Essas coisas não são duplamente exclusivas, não são excludentes, mas eu acho que é mais ou menos isso" (ENTREvistado 4). 
O ENSINO DOS ESTUDOS ORGANIZACIONAIS NAS INSTITUIÇÕES BRASILEIRAS: UM ESTUDO EXPLORATÓRIO NOS CURSOS DE PÓS-GRADUAÇÃO STRICTO SENSU DE ADMINISTRAÇÃO

Figura I Programa I (disciplina Teoria das Organizações/Mestrado e Doutorado), 2008
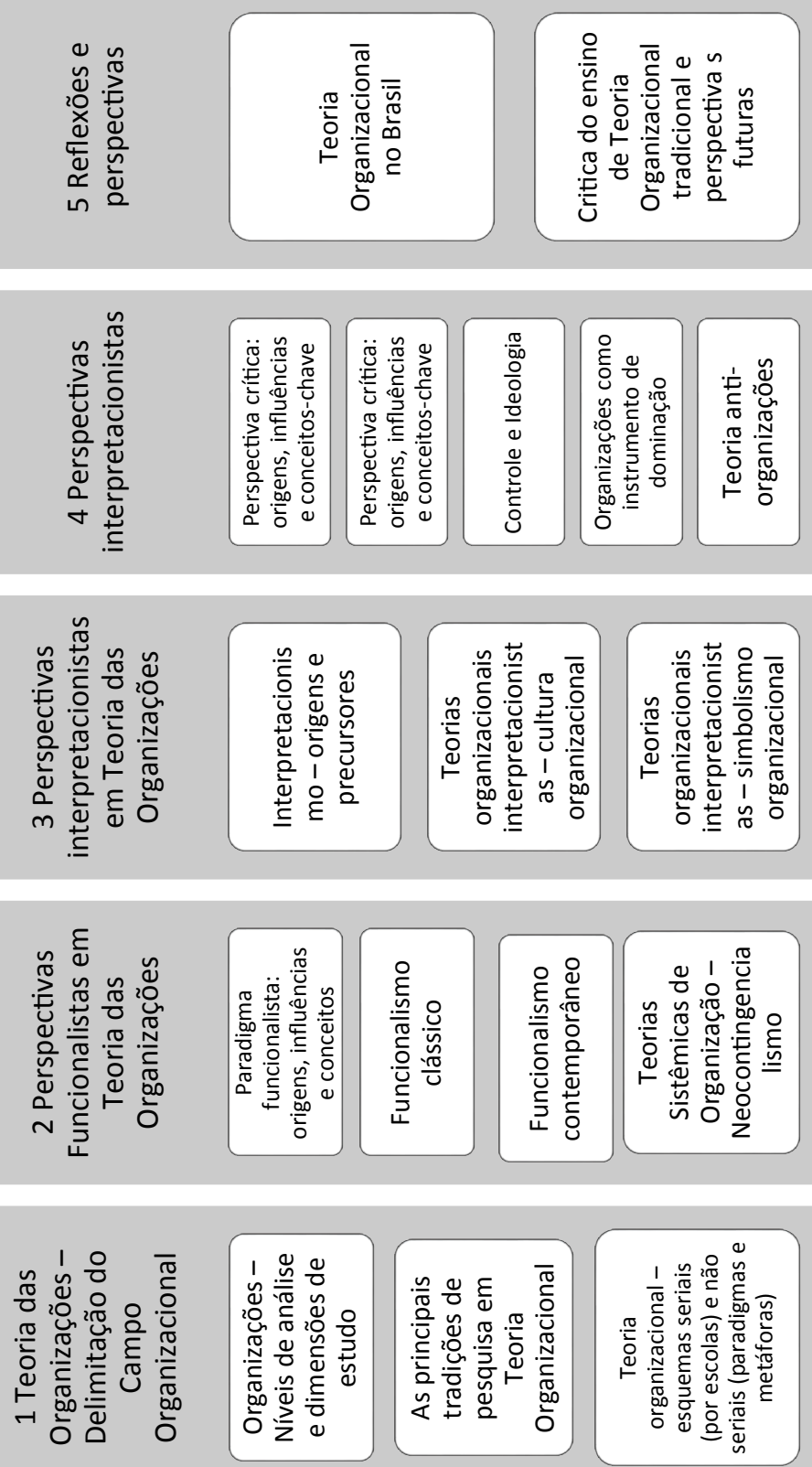
Percebe-se na organização dos conteúdos (Figura I) uma influência dos paradigmas da análise de Burrel e Morgan (1979), quando categorizam o conhecimento nas perspectivas funcionalistas, interpretacionistas e críticas. Além disso, ao subdividir as perspectivas em fases de desenvolvimento (funcionalismo clássico, contemporâneo e neocontingencialismo), o docente destaca que os Estudos Organizacionais no Brasil tiveram um desenvolvimento diferente do contexto internacional. Finalmente, o docente discute as diferenças dos EO no Brasil.

O professor explica que seleciona o material ensinado com base em dois critérios: "primeiro, eu acho é o próprio estado do campo, a gente tem procurado dar aos alunos uma visão atualizada do campo. [...] Isso é um dado importante. Segundo, acho que são influenciados também pelo tipo de curso que eu ensino, se for um curso de mestrandos, para mestres e doutores, ali no sentido de mestrado strictu sensu, eu seguramente vou procurar um tipo de material, provavelmente material mais acadêmico, artigos clássicos da área e algumas coisas mais recentes, vamos dizer, eu sempre enfatizo o que é mais clássico da área” (ENTREvistado 4).

A construção do desenho do Plano de Ensino I está vinculada à experiência do professor na área de Administração e ao acúmulo do seu conhecimento sobre EO. Apesar da discussão sobre o problema da incomensurabilidade dos paradigmas, o professor organiza o seu conteúdo de acordo com a proposição de Burrel e Morgan (1979), mas realiza uma discussão em sala de aula sobre as peculiaridades dessa construção no Brasil.

O segundo Plano de Ensino analisado (Figura 2) segue um desenho mais tradicional, encontrado em muitos cursos de graduação de Administração e em manuais de Teoria Geral da Administração. No caso da disciplina analisada, o docente reproduziu os temas do livro "Teoria Geral da Administração" de Motta e Vasconcelos (2002). Todavia, não se percebe no plano de ensino um momento para a discussão mais contextualizada dos EO no Brasil, como esclarece o objetivo da disciplina "é uma disciplina de nivelamento do conhecimento sobre a evolução do pensamento administrativo". 
O ENSINO DOS ESTUDOS ORGANIZACIONAIS NAS INSTITUIÇÕES BRASILEIRAS: UM ESTUDO EXPLORATÓRIO NOS CURSOS DE PÓS-GRADUAÇÃO STRICTO SENSU DE ADMINISTRAÇÃO

Figura 2 Plano de ensino 2 (Disciplina Teorias Organizacionais / Mestrado, 2008)

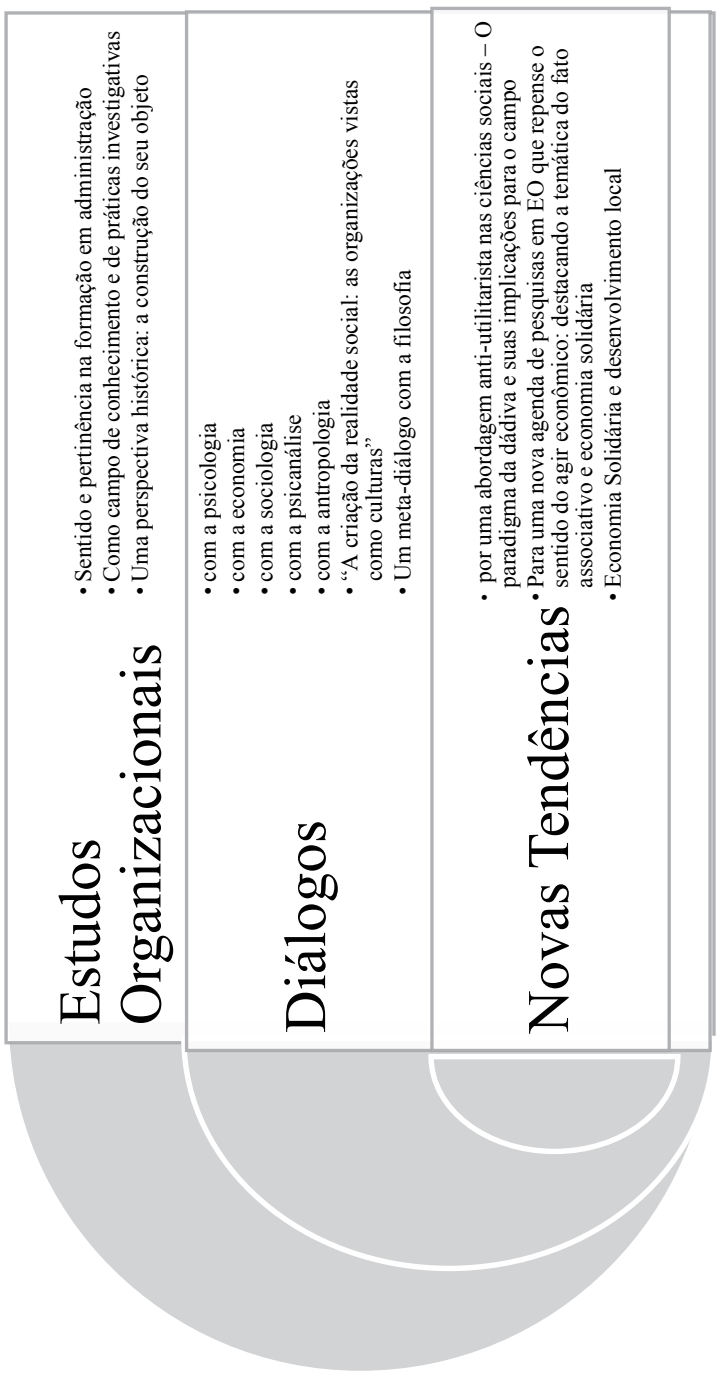


O professor ressalta que os conteúdos da graduação, mestrado e doutorado se repetem, todavia há uma maior complexidade ou aprofundamento na sua apresentação para os níveis da pós-graduação, mestrado e doutorado.

Todavia, essa não é uma opinião unânime, na pós-graduação há mestrados e doutorados integrados em que os estudantes assistem a mesma disciplina. Como citou o entrevistado 4: "Não faço distinção. Na nossa escola, [...] as aulas de Mestrado e Doutorado são conjuntas. Não há ainda seminários exclusivamente doutorais. É necessário, talvez, separar mais claramente, esses dois níveis". Para o entrevistado I7:

A graduação necessita ter conteúdos que possibilitem amarrar mais a vivência do aluno, com a idade que ele tem, com a sua experiência de vida, aquele mesmo assunto você pode dar no doutorado, só que ele se reveste de mil possibilidades, de mil teorias. [...] A diferença existe na medida em que da graduação para o doutorado, você vê cada vez mais se encaminhando para a pluralidade de teorias. [...] Na graduação você tem que colocar os pés no chão, não se pode abrir o leque deste jeito. Como você não abre para uma criança. $\mathrm{Na}$ medida em que você vai caminhando, no doutorado, você vai abrindo todos os leques do mundo.

Para o entrevistado I5: "são níveis diferentes da exploração dos mesmos fenômenos, então, eu acho que você tem uma compreensão progressiva do fenômeno organizacional, a própria organização enquanto fenômeno e a gestão enquanto processo [...]”'. O entrevistado 15 ainda complementa que:

No mestrado, o aluno se situa num campo puro e paradigmático; na Graduação, ele se situa num fenômeno, enquanto parte dele entende um pouco melhor de si, mesmo como participante de múltiplas organizações, simultaneamente; e, no Doutorado, ele tem um problema para resolver, um problema que tem uma ancoragem conceitual, e essa ancoragem conceitual é um problema que envolve um mundo empírico, envolve o mundo da prática ou das práticas, mas na verdade você tem uma questão a resolver que extrapola, ultrapassa, e ao ultrapassar, extrapola esse mundo você está contribuindo para o conhecimento. Conforme o entrevistado 15 , a diferença se dá muito mais em relação ao próprio objetivo da pós-graduação, sendo que no doutorado o estudante deveria resolver um problema com base em uma proposta inovadora. 
O Plano de Ensino 3 (Figura 3) remete a uma análise distinta dos Estudos Organizacionais.

Figura 3 Plano de ensino 3 (Disciplina Estudos Organizacionais/Mestrado)

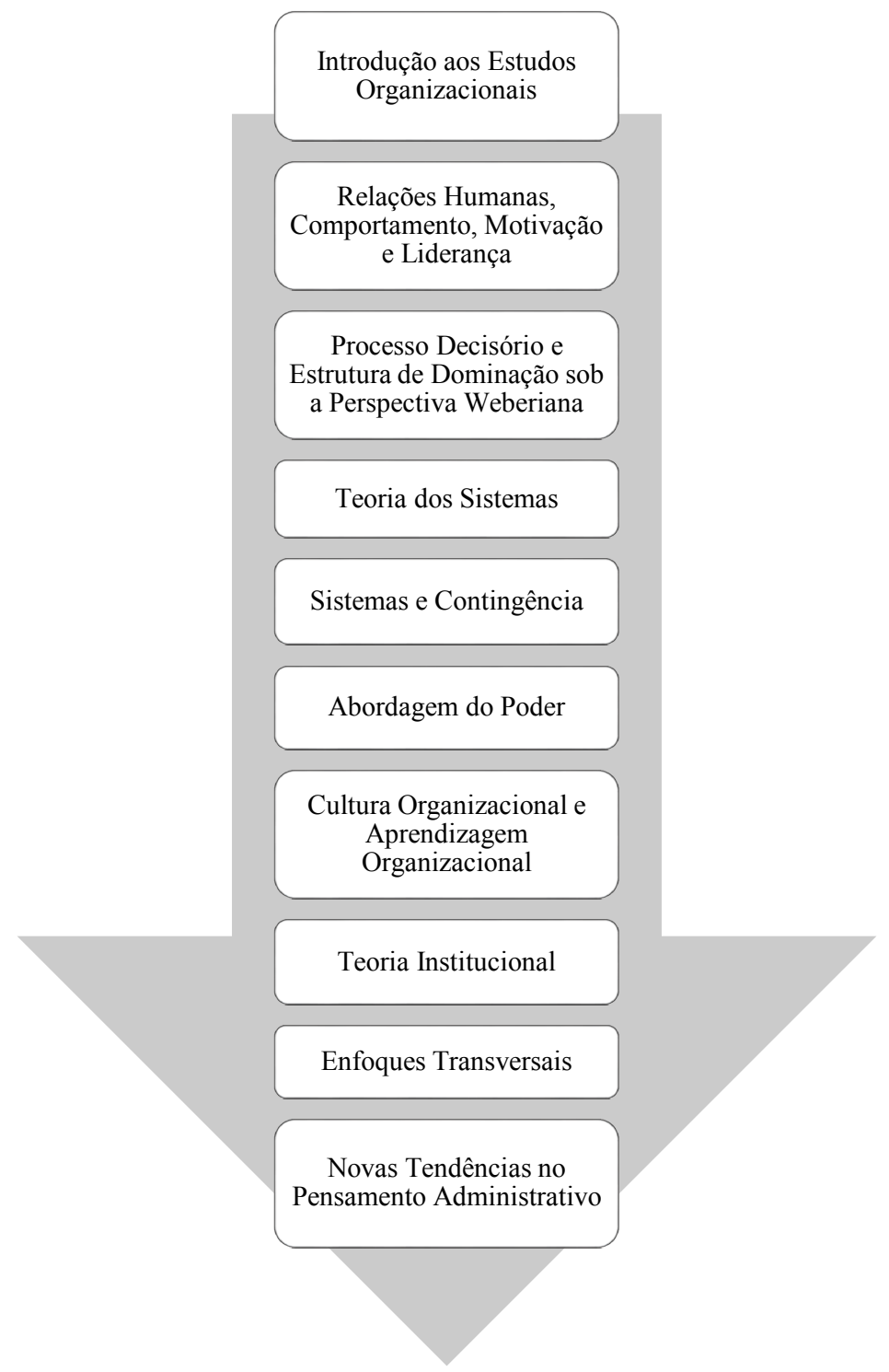


O plano de ensino 3 (Figura 3) revela a estratégia do professor da disciplina Estudos Organizacionais. Num primeiro momento, apresenta o campo de EO, esclarecendo a natureza do conhecimento produzido nesta área, suas principais matrizes epistemológicas e tendências de pesquisa. Essa apresentação segue uma abordagem histórica da evolução das ideias e marcos teóricos referenciais que conformam o campo e problematiza o seu objeto, ressaltando o caráter interdisciplinar dos EO. Num segundo momento, empreende um diálogo dos EO com cinco disciplinas das ciências humanas que contribuíram para a construção do conhecimento: Psicologia, Economia, Sociologia, Psicanálise, Antropologia, finalizando com metadiálogo com a Filosofia. Num terceiro momento, apresenta os EO com base em uma abordagem "anti-utilitarista" e discute o paradigma da dádiva e suas implicações para o campo. O professor entrevistado 9 ressalta a questão da inovação em sua disciplina:

Eu acho que a abordagem baseada em seis diálogos é uma abordagem inovadora, pelo fato de aprofundar mais o olhar sobre Ciências Humanas básicas [...] e também de tentar se construir uma ponte, baseada em um diálogo com a Sociologia, a gente vai resgatar um pouco da tradição das chamadas sociologia das organizações, que é verdade uma matriz mais institucionalista, mas vai trazendo até uma discussão chamada Sociologia da Associação, que é uma proposta de J. L. Laville e R. Sainsaulieu Lazzili na França, muito interessante, que marca uma mudança importante em relação a porte crozieriano3.

Ao final, o professor enfatiza formas particulares de expressão do fenômeno organizacional, identificadas a noção de fato associativo, especialmente a temática da economia solidária, tema de interesse em suas pesquisas.

Sintetizando, os docentes para abranger todo o campo dos EO ensinam temas que não são do seu "gosto", mas também aproveitam a sala para discutir tópicos de seu interesse, mesmo não estando declarados em seu plano de ensino, como ficou claro nas entrevistas e plano de ensino analisados.

Com base na análise das 688 referências citadas nos nove Planos de Ensino das disciplinas de mestrado/doutorado4 (Quadro 4), verificou-se 
que o livro mais utilizado para o ensino no mestrado foi o Handbook of Organizational Studies (CLEGG; HARDY; NORD, 1998), cuja edição brasileira foi organizada por Miguel Caldas, Roberto Fachin e Tânia Fischer. O livro não é adotado como livro texto pelos docentes, mas diversos artigos da compilação foram citados. O Quadro 4 mostra os principais artigos e livros adotados pelos professores.

Quadro 4 Obras e autores mais utilizados para o ensino dos EO

\begin{tabular}{|c|c|c|}
\hline Planos & Título & Autor(es) \\
\hline 10 & $\begin{array}{l}\text { Teorização Organizacional: um Campo } \\
\text { Historicamente Contestado }\end{array}$ & Michael Reed (1998) \\
\hline 10 & Teoria da Contingência Estrutural & Lex Donaldson (1998) \\
\hline 10 & $\begin{array}{l}\text { Economia das Organizações: Entendendo a } \\
\text { Relação entre as Organizações e a Análise } \\
\text { Econômica }\end{array}$ & Jay B. Barney; William Hesterly (2004) \\
\hline 07 & $\begin{array}{l}\text { A nova ciência das organizações: uma } \\
\text { reconceituação da riqueza das nações }\end{array}$ & Alberto Guerreiro Ramos (1981) \\
\hline 07 & Organização e poder: empresa, Estado e escola & Fernando Carlos Prestes Motta (1976) \\
\hline 07 & O que é burocracia? & Fernando Carlos Prestes Motta (1985) \\
\hline 05 & Burocracia e Ideologia & Maurício Tragtenber g (1974) \\
\hline 05 & Administração, Poder e Ideologia & Maurício Tragtenberg (1980) \\
\hline 05 & Economia e Sociedade & Max Weber (1994) \\
\hline 05 & Imagens da Organização & Gareth Morgan (1980) \\
\hline 05 & $\begin{array}{l}\text { Paradigma funcionalista: desenvolvimento de } \\
\text { teorias e institucionalismo nos anos } 1980 \text { e } 1990\end{array}$ & Miguel P. Caldas; Roberto Fachin (2007) \\
\hline 05 & $\begin{array}{l}\text { Debates e perspectivas centrais na teoria das } \\
\text { organizações }\end{array}$ & $\begin{array}{l}\text { W. Graham Astley; Andrew H.Van de } \\
\text { Ven (1983) }\end{array}$ \\
\hline 05 & $\begin{array}{l}\text { A gaiola de ferro revisitada: isomorfismo } \\
\text { institucional e racionalidade coletiva nos } \\
\text { campos organizacionais } 5\end{array}$ & $\begin{array}{l}\text { Paul J. DiMaggio: Walter W. Powell } \\
\text { (1983) }\end{array}$ \\
\hline
\end{tabular}

A utilização do Handbook possibilita um mapeamento do conhecimento do campo oferecendo um levantamento da diversidade de perspectivas na década de 1990. Essa obra possibilitou a legitimização de perspectivas críticas e pós-críticas em organizações no Brasil que desde 1980 tinham se popularizado baseado no conceito de paradigmas (CALDAS, 2005; RODRIGUES; CARrieri, 200I). Conforme Caldas (2005, p. 8), "O uso de Burrel e Morgan 
para a formação de mestres e doutores foi intensivo, [...] pelas mãos de professores tais como Fernando C. Prestes Motta, Carlos Osmar Bertero, Maria Tereza Fleury, Sylvia Vergara, Clóvis Machado-da-Silva, Roberto Fachin e Tânia Fischer, entre muitos outros". De acordo com um dos planos de ensino apresentados, percebe-se que ainda há uma forte influência dessa concepção de análise.

Cerca de $60 \%$ das referências bibliografias das 688 analisadas são de autores estrangeiros de origem anglo-saxão e francesa. Consequentemente, isso se reproduz na própria produção acadêmica nacional, como foi pesquisado por Machado-da-Silva, Cunha e Amboni (1990), Bertero e Keinert (1994), Rodrigues e Carrieri (200I) e Vergara (2005).

Apesar desta predominância estrangeira, verificou-se um movimento de um grupo de docentes de resgate de autores brasileiros como de Alberto Guerreiro Ramos, Celso Furtado, Fernando Carlos Prestes Motta, Gilberto Freyre e Maurício Tragtenberg, buscando contextualizar os EO no país. Nesse sentido mais da metade dos Planos de Ensino de disciplinas obrigatórias contemplam um ou mais encontros para discutir a contribuição brasileira para os EO, além de alguns programas oferecerem disciplinas optativas com esse objetivo.

Alguns autores brasileiros são citados esporadicamente relacionados aos assuntos discutidos no Plano de Ensino como: funcionalismo (Miguel Caldas e Roberto Fachin), teoria neo-institucional e poder (Cristina Carvalho e Marcelo Milano Vieira), poder (José Henrique de Faria), teoria crítica (Maria Ceci Misoczky, Rafael Alcadipani, Ana Paula Paes de Paula), estrutura/ institucionalismo (Clovis Luiz Machado-da-Silva, João Crubellate), Estudos Organizacionais (Carlos Bertero, Tânia Fischer, Sylvia Vergara), novas formas organizacionais (Eloise Dellagnelo), cultura (Neusa Cavedon, Maria Ester de Freitas, Alexandre de Pádua Carrieri e Pedro Jaime Junior), mudança organizacional (Thomaz Wood Jr.), economia solidária (Genauto França Filho), análise psicossocial (Antônio Virgílio Bittencourt Bastos), dentre outros.

Essa pluralidade reflete a diversidade de formação universitária dos docentes que deriva da Administração, Biblioteconomia, Ciências Contábeis, 
Ciências Econômicas, Direito, Filosofia, Pedagogia, Psicologia e Sociologia. Assim, da mesma forma que se convive com o problema de identidade dos Estudos Organizacionais também se pode escolher uma diversidade de objetos de estudo, de recortes, de perspectivas etc.; o que seria do campo dos Estudos Organizacionais se limitasse as suas possibilidades?

O processo de ensino impacta nos desafios levantados pelos professores entrevistados para a delimitação do campo dos Estudos Organizacionais.

O primeiro desafio enfatizado pelos entrevistados refere-se à aplicabilidade da teoria para a solução de problemas organizacionais. Baseado nas pesquisas verificou-se que a maior parte dos professores reproduz esse primeiro desafio baseado nas seguintes ações:

A O objetivo das disciplinas obrigatórias está relacionado com a compreensão do conjunto da teoria, não há uma preocupação no sentido de relacionar a teoria com a prática nas organizações.

B Nos cursos acadêmicos, os professores tendem a privilegiar materiais predominantemente teóricos, como obras clássicas e artigos de eventos e revistas acadêmicas; a seleção de artigos teórico/empíricos é pouco realizada. Além disso, percebe-se uma valorização muito forte da teoria dos Estudos Organizacionais no próprio discurso dos professores, ressaltando a divisão entre a seleção dos cursos profissionalizantes e dos cursos acadêmicos.

C Poucos professores utilizam simulações (estudos de caso, dossiê de imprensa etc.) em suas modalidades de ensino-aprendizagem, que pode trazer uma desconexão entre teoria e realidade organizacional. O segundo desafio é com relação à descontextualização do conhecimento à realidade brasileira. A pesquisa mostrou que cerca de $60 \%$ das referências bibliográficas lecionadas nas disciplinas é de origem anglo-saxão e francesa. Este pode ser um indicador da reprodução do conhecimento descontextualizado na comunidade científica, mas não há como confirmar, pois não foram realizadas pesquisas em sala de aula ou com os estudantes. Todavia, verificaram-se esforços no sentido de contextualizar tal realidade: 
A Os programas tendem a inserir disciplinas que discutam, especificamente, os Estudos Organizacionais no Brasil, como na FGV e UFMG.

в Os professores reservam encontros em suas disciplinas obrigatórias, no mestrado e doutorado, para discutir a produção brasileira.

C Verificou-se um movimento entre os professores de resgate e utilização de autores brasileiros.

D Entre as modalidades de ensino-aprendizagem foram destacados a utilização de recursos estéticos como literatura clássica e filmes brasileiros para contextualizar a teoria discutida.

Um terceiro desafio diz respeito às dimensões micro e macro de análise. Verificou-se que a maior parte dos currículos contempla disciplinas tanto relacionadas à dimensão macro como à dimensão micro. Essa divisão está presente desde o início dos cursos de graduação em Administração. Todavia, percebe-se uma tendência de valorização das dimensões micro, ou seja, da discussão de temas mais relacionados com o indivíduo, principalmente, da delimitação dos EO nas subdivisões da ANPAD. Os EO têm se tornado uma subdivisão da ANPAD muito crítica, se afastando do paradigma funcionalista, até então, dominante. Essa tendência ainda não influenciou o campo nos currículos.

O quarto desafio está relacionado à incomensurabilidade dos paradigmas propostos por Bürrel e Morgan (1979), ou seja, para alguns teóricos, não é possível combinar as perspectivas na realização de pesquisas. O discurso da maioria dos professores foi no sentido de ressaltar o diálogo entre paradigmas distintos; assim, a seleção e organização do conhecimento, na maioria dos programas, não têm contemplado essa tese dos autores.

O quinto desafio levantado pelos entrevistados refere-se à qualidade da publicação brasileira e à dificuldade de publicação no exterior. $A$ pesquisa mostrou que a maior parte dos professores possui inserção internacional por meio de publicação em eventos; todavia, são escassas as publicações em periódicos internacionais e publicação de livros no exterior. Bertero (2006) ressaltou que tal fato pode estar ligado à própria atualização dos autores e do grau de exigência das revistas internacionais; porém, 
não se conseguiu aferir isso na pesquisa. Tanto essa dificuldade quanto a qualidade da publicação brasileira podem estar ligadas à diversidade de atividades que o professor desempenha, o que dificulta a sua dedicação à publicação. Alguns entrevistados sugeriram que a baixa qualidade da publicação brasileira estaria relacionada à exigência da realização de artigos dos estudantes durante o curso das disciplinas, devido ao fato de os alunos não estarem preparados para a publicação. A submissão desses artigos, além de tudo, sobrecarregaria os avaliadores, aumentando a porcentagem de erros de avaliação. 


\section{CONSIDERAÇÕES FINAIS}

O propósito do artigo foi analisar como se ensina o campo dos Estudos Organizacionais nos cursos de pós-graduação em nove Programas de Pós-Graduação Stricto Sensu no Brasil. Para tal, realizou-se uma pesquisa exploratória descritiva, por meio de análise documental e entrevistas semiestruturadas. Dadas essas características, é importante destacar que não cabem conclusões de causa e efeito neste trabalho, mas levantar informações do processo de ensino para refletir e reavaliar o desenvolvimento do campo nos Programas de Pós-Graduação Stricto Sensu em Administração.

O ensino do campo de Estudos Organizacionais, materializado com base no design curricular, não é determinado isoladamente por professores, embora estes sejam o seu principal influenciador, mas construído socialmente pela participação das instituições de ensino superior e pela sociedade mais ampla. Além disso, o ensino é processo histórico, no qual estiveram presentes rupturas, ambiguidades e conflitos, tanto quanto cooperação e consensos.

Os resultados da pesquisa mostraram que o campo dos EO se constitui em um eixo estruturador do currículo nos nove Programas de Pós-Graduação Stricto Sensu pesquisados - EAESP/FGV/SP, EBAPE/FGV/RJ, UFBA, UFMG, UFPE, UFPR, UFRGS, UFSC e UNB. O campo é configurado nesses currículos por meio da oferta de pelo menos uma disciplina obrigatória focada na evolução da teoria (como teoria geral da administração, teoria das organizações, estudos organizacionais ou análise organizacional) e de outras disciplinas eletivas ou optativas relacionadas à área de concentração do curso e aos próprios interesses dos professores do programa. Essas disciplinas são reflexivas da estabilidade e transformações paradigmáticas do campo, sendo representadas por meio de teoria específica ou campo de estudo em especial, como comportamento organizacional, estratégia organizacional, desenvolvimento organizacional, antropologia organizacional, dentre outras; por temas relevantes da área, como liderança, tomada de decisão, poder e conflito; ou, ainda, por recortes paradigmáticos (funcionalismo no Brasil, interpretacionismo etc.). 
Os currículos dos Programas de Pós-Graduação Stricto Sensu, a partir de 2000, passaram por uma série de mudanças, dentre as quais se destaca a integração das disciplinas do mestrado e doutorado, cujo ensino é realizado em uma mesma sala de aula. Se, por um lado, essa recomendação da CAPES gera uma redução dos custos do ensino e aproveitamento da estrutura organizacional das Instituições de Ensino, por outro lado, os conteúdos sobre o campo são ensinados sem aprofundamento em cada nível, sendo repetitivos e não estruturados. Apesar desse contexto, a maior parte dos entrevistados destacou a importância de se realizar um aprofundamento em cada nível de ensino. Com base nessa informação, percebe-se a dificuldade de se estabelecer novos modelos de currículos. As instituições de ensino precisam reavaliar as mudanças e construir novas possibilidades de ensino, quiçá, modalidades de ensino externas à sala de aula, que contemplem um aprofundamento distinto entre esses dois níveis.

É relevante ressaltar que apesar dos Programas focarem a formação de professores e pesquisadores, a maior parte deles não oferece atividades focadas no ensino e promoção de habilidades e competências para o exercício da docência. Os estudantes normalmente aprendem externamente ao curso nas práticas do dia a dia da sala de aula, sem a orientação dos professores.

Os conteúdos selecionados para ensino nos programas estudados podem de maneira geral ser classificados em três categorias centrais: as teorias organizacionais (estruturalismo, pós-estruturalismo, teoria da burocracia, teoria dos sistemas, contingencialismo, institucionalismo e neo-institucionalismo), os temas (tópicos) transversais (conflito, controle, cultura, dominação, estrutura, indivíduo, poder e processo decisório) e as escolas ou perspectivas (a escola crítica, funcionalista e interpretacionista e a perspectiva brasileira). Esses conteúdos são organizados nos planos das disciplinas baseado em três formas preponderantes: a evolução histórica dos paradigmas ou escolas, discussão de recortes de temas transversais e diálogos com as diferentes ciências.

A organização do conhecimento nos currículos é ilustrativa do desenvolvimento do próprio campo do conhecimento. Todavia, percebemse algumas diferenças entre os programas, devido, principalmente, à 
formação do seu corpo docente. Dessa forma, os conteúdos ensinados no campo dos EO passam por ampliações, inclusões e exclusões de acordo com as mudanças no corpo docente da instituição ou a interação entre docente de outros programas.

Os autores mais utilizados para o ensino desses conteúdos são estrangeiros, devido à própria construção da teoria que se desenvolveu fora do Brasil; mas, percebe-se um esforço de discussão dos EO com base no contexto brasileiro.

Os conteúdos selecionados e organizados nos currículos são atualizados, conforme os professores entrevistados, a cada oferta da disciplina, levandose em conta a discussão realizada no âmbito nacional, principalmente, nos eventos realizados pela ANPAD. Com menor destaque, foram citados os eventos e periódicos internacionais. Assim, os professores mantêm os conteúdos, porém inserem autores mais recentes nas discussões. Assim, o terceiro pressuposto de que os conteúdos são selecionados distantes das discussões internacionais recentes não pode ser comprovado pela pesquisa, pois os assuntos ensinados estão muito próximos das temáticas debatidas internacionalmente (como Academy of Management e Europeans Group of Organizational Studies). Acredita-se que uma pesquisa mais aprofundada deveria ser empreendida para verificar essa defasagem, pois alguns programas das disciplinas inserem um tópico para o debate das perspectivas futuras nos Estudos Organizacionais, mas não fazem menção nos seus programas sobre quais seriam. Essa foi uma lacuna da pesquisa, pois não se perguntou aos professores o que eles ensinavam nas perspectivas futuras.

Os conteúdos ensinados no campo dos EO são influenciados pelas relações de poder ao longo do tempo foi comprovado na pesquisa, pois os conteúdos ensinados sobre o campo são os mesmos recortados pelos principais grupos de pesquisa dos nove programas estudados, os quais são referências na área de Administração. Além disso, os entrevistados ressaltaram que a construção do campo está muito relacionada a professores que participam da ANPAD, mas todos os professores citados pelos entrevistados possuem pesquisas e publicações que conformam campos de interesse de estudo. Também a ANPAD influencia a seleção dos conteúdos para ensino, já que esta é formada pelos próprios pesquisadores. 
Além dos resultados, também é importante ressaltar algumas limitações e direcionamentos para pesquisas futuras. Embora os nove programas pesquisados sejam representativos dos I8 programas que oferecem mestrado e doutorado acadêmico, em Administração, regulamentados pela CAPES, tem-se que considerar que seria importante ampliar a abrangência da pesquisa além desse núcleo bruto, já que em 2009, aproximadamente 90 programas estão regulamentados pela CAPES, comportando também os cursos profissionais e, mais recentemente, os interdisciplinares. Assim, seria importante realizar uma pesquisa contemplando os cursos profissionais para verificar se os conteúdos são distintos na formação de acadêmicos e profissionais.

Outra sugestão seria ampliar o nível de análise para a graduação e verificar como se dá o aprofundamento do conteúdo em relação à graduação e pósgraduação e mesmo dentro da pós-graduação (acadêmica e profissional).

A pesquisa exploratória possibilitou uma compreensão mais ampla da configuração e do ensino dos Estudos Organizacionais nos Programas de Pós-Graduação Stricto Sensu, mas impediu o aprofundamento desta pesquisa. Desse modo, poderia se realizar estudos de caso mais aprofundados historicamente para compreender a construção dos EO em cada programa ao longo do tempo e a participação do seu corpo docente nessa construção.

A pesquisa focou os documentos das instituições e a voz dos professores que são responsáveis pela seleção e organização do conhecimento nos currículos. Apesar da sua importância, sentiu-se em diversos momentos a necessidade de dar voz aos estudantes, principais interessados no processo de aprendizagem. Uma sugestão nesse sentido seria realizar pesquisas sobre a importância dos Estudos Organizacionais no processo de aprendizagem dos estudantes e como os Estudos Organizacionais contribuem para a aprendizagem desses estudantes e para as áreas mais funcionais da Administração. 


\section{REFERENNCIAS}

AIRES, J. A.; ERN, E. A influência dos professores na construção das disciplinas escolares: o caso da Química em uma instituição de ensino secundário catarinense. In: ENANPED, 28., 2005, Caxambú/MG. Anais... Caxambú/MG: ANPED, 2005.

ASTLEY, W. G.; VAN DE VEN, A. H. Central Perspectives and debates in organizaton theory. Administrative Science Quaterly, v. 28, n. 2, p. 245-273, 1983.

ALVES, F. M. S.; REINERT, J. N. A Multidisciplinaridade no Curso de Graduação em Administração: estudo de Caso da UFSC. In: Simpósio de Gestão e Estratégia em Negócios, 4., Rio de Janeiro, 2006. Anais... Rio de Janeiro, 2006.

BARDIN, L. Análise de Conteúdo. Lisboa (Portugal): Edições 70, 1977.

BARNEY, J. B.; HESTERLY, W. Economia das organizações: entendendo a relação entre as organizações e a análise econômica. CLEGG, S. R.; HARDY, C.; NORD, W. R. Handbook de Estudos Organizacionais, v. 1. São Paulo: Atlas, 1998.

BERTERO, C. O. Ensino e pesquisa em Administração. São Paulo: Thomson Learning, 2006.

BERTERO, C. O.; KEINNERT, T. M. M. A evolução da Análise Organizacional no Brasil (1961-93). Revista de Administração de Empresas, v. 34, n. 3, p. 81-90, 1994.

BERTERO, C. O.; ALCADIPANI, R. Guerra fria e ensino do management no Brasil: o caso da FGV-EAESP. Revista de Administração de Empresas, v. 52, n. 3, p. 284-299, 2012.

BERTERO, C. O. ; Alcadipani, R.; Cabral, S.; Faria, A.; Rossoni, L. Os desafios da produção de conhecimento em Administração no Brasil. Cad. EBAPE.BR, v. 11, n. 1, p. 181-196, 2013.

BITTENCOURT, C. M. F. Disciplinas escolares: história e pesquisa. In: OLIVEIRA, M. A. T.; RANZI, S. M. F. (Orgs.) História das disciplinas escolares no Brasil: contribuições para o debate. Bragança Paulista: EDUSF, 2003.

BURREL, G.; MORGAN, G. Sociological paradigms and organizational analysis. London: Heinemann Educational Books, 1979.

CALDAS, M. P. Paradigmas em Estudos Organizacionais uma introdução à série. Revista de Administração de Empresas, v. 45, n. 1, p. 53-57, 2005.

CALDAS, M. P.; BERTERO, C. O. Teorias da Organização. São Paulo: Atlas, 2007.

CALDAS, M. P.; FACHIN, R. Paradigma Funcionalista: desenvolvimento de teorias e institucionalismo nos anos 1980 e 1990. In: CALDAS, M. P.; BERTERO, C. O. (Coord.). Teoria das Organizações. São Paulo: Atlas, 2007.

CASTRO, C. M. O ensino da administração e seus dilemas: notas para debate. Revista de Administração de Empresas, v. 21, n. 3, p. 58-61, 1981.

CHANLAT, J. F. Ciências sociais e management: reconciliando o econômico e o social. São Paulo: Atlas, 1999. 
CHERVEL, A. História das disciplinas escolares: reflexão sobre um campo de pesquisa. Teoria e Educação, n. 2, p. 177-229, 1990.

CLEGG, S. R.; HARDY, C. Organização e Estudos Organizacionais. In: CLEGG, S. R; HARDY, C.; NORD, W. R. Handbook de Estudos Organizacionais, v. 1. São Paulo: Atlas, 1998.

CLEGG, S. R; HARDY, C.; NORD, W. R. Handbook de Estudos Organizacionais. São Paulo: Atlas, 1996.

DIMAGGIO, P. J.; POWELL, W. W. The iron cage revisited: institutional isomorphism and collective rationality in organizational fields. American Sociological Review, v. 48, n. 2, p. 147-169, 1983.

DONALDSON, L. Teoria da Contingência Estrutural. In: CLEGG, S. R.; HARDY, C.; NORD, W. R. Handbook de Estudos Organizacionais, v. 1. São Paulo: Atlas, 1998.

FERREIRA, M. S.; MOREIRA, A. F. B. A história da disciplina escolar Ciências nas dissertações e teses brasileiras no período 1981-1995. Ensaio - Pesquisa em Educação em Ciências, v. 3, n. 2, 2001.

FISCHER, T. A Difusão do Conhecimento sobre Organizações e Gestão no Brasil: Seis Propostas de Ensino para o Decênio 2000/2001. Revista de Administração Contemporânea, v. 5, n. 21, p. 121-140, 2001.

FISCHER, T. A formação do administrador brasileiro na década de 90: crise, oportunidade e inovações nas propostas de ensino. Revista de Administração Pública, v. 27, n. 4, p. 11-20, 1993.

FISCHER, T. Alice através do espelho ou Macunaíma em Campus Papagalli? Mapeando Rotas de Ensino dos Estudos Organizacionais no Brasil. Revista Organizações \& Sociedade, v. 10, n. 28, p. 47-62, 2003.

FISCHER, T. A. Modalidades de Ensino-Aprendizagem nos Currículos dos Cursos de Mestrado em Administração no Brasil. 1977. Dissertação (Mestrado em Administração) Universidade Federal do Rio Grande do Sul, 1977.

FISCHER, T.; WAIANDT, C.; SILVA, M. R. Estudos Organizacionais e Estudos Curriculares: Trajetórias Simétricas e Convergências Inevitáveis. In: Encontro Nacional de Estudos Organizacionais, 4., Porto Alegre, 2006. Anais... Porto Alegre: Anpad, 2006.

GODOY, A.S.; MOREIRA, D.A; TAKEI A.T. Análise dos Planos de Ensino das Disciplinas Ligadas às Teorias da Administração nos Cursos Superiores de Administração de Empresas no Município de São Paulo. In: EnANPAD, 21., 2002, Salvador. Anais... Salvador: Anpad, 2002.

GOODSON, I. F. Currículo: teoria e história. Petrópolis, Rio de Janeiro: Vozes, 1995. GOODSON, I. F. Estudio del curriculum: casos Y métodos. Buenos Aires: Amorrortu, 2003.

GOODSON, I. F. O currículo em mudança: estudos na construção social do currículo. Portugal: Porto, 2001. 
JULIA, D. Disciplinas escolares: objetivos, ensino e apropriação. In: LOPES, A. C.; LEVI MACEDO, E. (Orgs.). Disciplinas e integração curricular: história e políticas. Rio de Janeiro: DP\&A, 2002.

KINCHELOE J. L. Introdução por Joe L. Kincheloe. In: GOODSON, I. F. O currículo em mudança: estudos na construção social do currículo. Porto (Portugal): Porto, 2001. p. 7-38.

LEVI, G. Uso de biografia. In: AMADO, J.; FERREIRA, M. M. (Coord.). Usos \& Abusos da história oral. 5.ed. Rio de Janeiro: FGV, 2002.

MACEDO, E. Currículo: Política, Cultura e Poder. Currículo sem Fronteiras, v. 6, n. 2, p. 98-113, 2006.

MACHADO DA SILVA, C.; CUNHA, V. C.; AMBONI, N. Organização: o estado da arte da produção acadêmica no Brasil. In: EnANPAD, 14., Belo horizonte. Anais... Belo Horizonte: Anpad, 1990.

MATTOS, P. L.; BEZERRA, D. M. Cursos de graduação de Administração: questões básicas para a estruturação de currículos. Revista de Administração Contemporânea, v. 5, n. 2, p. 141-160, 1999.

MORGAN, G. Imagens da Organização. São Paulo: Atlas, 1980.

MOTTA, F. C. P. O que é burocracia? São Paulo: Brasiliense, 1985.

MOTTA, F. C. P. Organização e Poder: Empresa, Estado e Escola. São Paulo: Atlas, 1976.

MOTTA, F. C. P.; VASCONCELOS, I. F. F. G. Teoria Geral da Administração. São Paulo: Pioneira Thomson Learning, 2002.

MOTTA, F. P. A questão da formação do administrador. Revista de Administração de Empresas, v. 23, n. 4, p. 53-55, 1983.

PACHECO, J. A. Processos Identitários nos Estudos Curriculares em Portugal. A leitura geométrica de Alfredo Veiga-Neto. In: Colóquio sobre Questões Curriculares, 5., 2002, Portugal. Anais... Braga: Centro de Investigação em Educação do Instituto de Educação e Psicologia da Universidade do Minho, 2002.

PESSANHA, E. C.; DANIEL, M. E. B.; MENEGAZZO, M. A. Da história das disciplinas escolares à história da cultura escolar: uma trajetória de pesquisa. Revista Brasileira de Educação, n. 27, 2004.

RAMOS, A. G. A nova ciência das organizações: uma reconceituação da riqueza das nações. Rio de Janeiro: FGV, 1981.

REED, M. Teorização Organizacional: um campo historicamente contestado. In: CLEGG, S. R; HARDY, C.; NORD, W. R. Handbook de Estudos Organizacionais, v. 1. São Paulo: Atlas, 1998.

ROCHA, G. O. R. A pesquisa sobre currículo no Brasil e história das disciplinas escolares. In: GONÇALVES, L. A. (Org.). Currículo e Políticas Públicas. São Paulo: Autêntica, 2003. 
RODRIGUES, S. B.; CARRIERI, A. P. A tradição anglo-saxônica nos estudos organizacionais brasileiros. Revista de Administração Contemporânea, Edição Especial, p. 81-102, 2001.

RODRIGUES, S. B.; CARRIERI, A. P. A Tradição Anglo-saxônica nos Estudos Organizacionais Brasileiros. Revista de Administração Contemporânea, v. 5, Edição especial, p. 81-102, 2001.

SANTOS, L. L. C. P. História das disciplinas escolares: perspectivas de análise. Teoria \& Educação, v. 2, n.1, p. 21-29, 1990.

JAIME Jr, P.; SERVA, M. Itinerários teóricos e práticas profissionais numa fronteira interdisciplinar: contribuições para o ensino em administração. Revista de Administração Pública, v.36, n. 5, p. 699-721, 2002.

SILVA, T. T. Apresentação. In: GOODSON, I. F. Currículo: teoria e história. Petrópolis/ RJ: Vozes, 1995. p. 7-14.

SKORA, C. M.; MENDES, D. As coisas novas: porque TGA parou no tempo. In: EnANPAD, 25., 2001, Campinas. Anais... Campinas: Anpad, 2001.

SOUZA JR., M.; GALVÃO, A. M. O. História das disciplinas escolares e história da educação: algumas reflexões. Educação e Pesquisa, v. 31, n. 3, p. 391-408, 2005.

TRAGTENBERG, M. Administração, poder e ideologia. São Paulo: Moraes, 1980.

TRAGTENBERG, M. Burocracia e ideologia. São Paulo: Ática, 1974.

VERGARA, S. C. Estudos organizacionais: a produção científica brasileira. In: BERTERO, C. O.; CALDAS, M. P.; WOOD Jr., T. (Org.). Produção Científica em Administração no Brasil. São Paulo: Atlas, 2005.

WEBER, M. Economia e Sociedade, Brasília: Editora UnB, 1994.

1 Max Weber, George Herbert Mead, Alfred Schutz, Erving Goffman, Peter L. Berger e Thomas Luckman (KINCHELOE, 2001, p. 8).

2 Incomensurabilidade, segundo Clegg e Hardy (1996), pressupõe que cada paradigma deve desenvolverse separadamente, perseguindo sua própria problemática, ignorando a problemática dos outros paradigmas, considerando-os inválidos, e que as diferentes constatações sobre as organizações, em um mundo ideal, sejam resolvidas à luz de suas implicações para a praxis social.

3 Referente aos trabalhos de Michel Crozier.

4 Foram catalogadas todas as referências dos docentes nas nove disciplinas obrigatórias numa planilha Excel, em seguida, foi contada uma referência da publicação em cada Plano de Ensino, não havendo múltipla contagem.

5 Foi publicado pela Revista de Administração de Empresas da FGV e posteriormente publicado no livro "Teoria das Organizações”, organizado por Miguel P. Caldas e Carlos Osmar Bertero (2007). 


\section{DADOS DOS AUTORES}

CLAUDIANI WAIANDT ${ }^{\star}$ CWAIANDT@IG.Com.BR

Doutora em Administração pela UFBA

Instituição de vinculação: Univerdade Federal da Bahia

Salvador/BA - Brasil

Áreas de interesse em pesquisa: Estudos Organizacionais, Ensino, História da Administração e Gestão Social.

*Av. Reitor Miguel Calmon, $s / n \quad$ Vale do Canela Salvador/BA 40110-903

\section{TÂNIA FISCHER taniafischer@ciags.org.br}

Doutora em Administração pela USP

Instituição de vinculação: Univerdade Federal da Bahia

Salvador/BA - Brasil

Áreas de interesse em pesquisa: Poderes Locais e Gestão Social do Desenvolvimento

Territorial, Organizações e Interorganizações, Gestão e Educação para a Gestão Social. 